Article

\title{
Aqueous Dehydration, Hydrogenation, and Hydrodeoxygenation Reactions of Bio-Based Mucic Acid over Ni, NiMo, Pt, Rh, and Ru on Neutral or Acidic Catalyst Supports
}

\author{
Brigita Hočevar, Miha Grilc *(1) and Blaž Likozar@ \\ Department of Catalysis and Chemical Reaction Engineering, National Institute of Chemistry, Hajdrihova 19, \\ 1000 Ljubljana, Slovenia; brigita.hocevar@ki.si (B.H.); blaz.likozar@ki.si (B.L.) \\ * Correspondence: miha.grilc@ki.si; Tel.: +386-1-4760540
}

Received: 11 January 2019; Accepted: 11 March 2019; Published: 20 March 2019

check for updates

\begin{abstract}
Hydrotreatment of mucic acid (also known as galactaric acid, an glucaric acid enantiomer), one of the most promising bio-based platform chemicals, was systematically investigated in aqueous media over alumina, silica, or carbon-supported transition (nickel and nickel-molybdenum) or noble (platinum, ruthenium and rhodium) metals. Mucic acid was only converted into mucic-1,4-lactone under non-catalytic reaction conditions in $\mathrm{N}_{2}$ atmosphere, while the $5 \mathrm{MPa}$ gaseous $\mathrm{H}_{2}$ addition triggers hydrogenation in the bulk phase, resulting in formation of galacturonic and galactonic acid. However, dehydroxylation, hydrogenation, decarbonylation, decarboxylation, and cyclization occurred during catalytic hydrotreatment, forming various partially and completely deoxygenated products with a chain length of 3-6 C atoms. Characterization results of tested catalysts were correlated with their activity and selectivity. Insufficient pore diameter of microporous supports completely hindered the mass transfer of reactants to the active sites, resulting in negligible conversion of mucic acid. A comprehensive reaction pathway network was proposed and several industrially interesting compounds were formed, including levulinic acid, furoic acid, and adipic acid. However, selectivity towards adipic acid, a bio-based nylon 6,6 precursor, was low (up to $5 \mathrm{~mol} \%$ ) in aqueous media and elevated temperatures.
\end{abstract}

Keywords: aldaric acid; biomass-derived chemicals; hydrodeoxygenation; heterogeneous catalysts; dicarboxylic acids; adipic acid

\section{Introduction}

A huge amount of interest is devoted to a search of new sources and processes for the production of industrially important chemicals, especially monomers, which can substitute petrol-based precursors. To avoid competition between food and chemical or fuel production, only non-edible biomass should be utilized in the chemical industry. The missed opportunities for converting biomass into chemicals lie in agricultural wastes, wood residues, and other similar lignocellulosic materials [1-3]. In general, lignocellulosic biomass is composed of three main polymer structures-lignin, cellulose, and hemicellulose. Each of them presents its own system of potential sources of chemicals [4]. Glucose as a cellulose monomer has a high potential for biopolymer production. Oxidation of a glucose at both terminal C-atoms yields a group of dicarboxylic sugar acids, named aldaric acids (saccharic acids), poorly soluble in polar and nonpolar solvents [5].

The main disadvantage utilization of cellulose as a feedstock for transportation fuels is a high oxygen/carbon ratio if compared to the petro-based ones. Oxygen-rich functional groups in cellulose, however, represent a huge potential for production of various chemicals. For that reason selective 
removal or transformation of certain functional groups by hydrodeoxygenation process (HDO) is adopted to get desired products. Few researchers devoted their work to the HDO of aldaric acids over transition or noble metals. Only a few patents and nearly no scientific papers are published on chemocatalytic conversion of aldaric acids (glucaric or mucic acid), most often towards adipic acid. Rennovia recently patented a process of glucose oxidation into glucaric acid over heterogenenous catalysts with air, where a progressive oxidation of the terminal functional groups (on C1 and C6 position) had proceeded. Two main routes are considered, and they both resulted in the same final product, glucaric acid [6]. Glucaric acid was converted further into adipic acid by a catalytic HDO process over different metal catalysts in an acidic environment, where acetic acid with additional $\mathrm{HBr}$ was used as a solvent. The highest yield ( $89 \%$ ) of adipic acid was reached from $\mathrm{RhPt} / \mathrm{Silica}$ catalyst. Asikainen et al. [7] presented and patented a process for selective dehydroxylation of aldaric acid into muconic acid or furanic chemicals. Homogeneous catalytic process was performed in different short chain alcohols over methylrhenium trioxide. The selectivity to linear or cyclic products depends on the reaction temperature. Higher temperatures $\left(>150{ }^{\circ} \mathrm{C}\right)$ resulted in cyclic products, while experiments performed at lower temperature $\left(<150^{\circ} \mathrm{C}\right)$ resulted in higher yields of linear products, esters of (di)carboxylic acids. Since alcohol was presented in abundant quantity, esterification proceeded between an alcohol solvent and carboxylic groups. Nevertheless, esters act as a protective group even though carboxylic group is more temperature-stable compared to the hydroxyl group. When carboxylic groups are protected, selective removal of hydroxyl groups can proceed. A comprehensive review of the catalytic hydrodeoxygenation of biomass-derived polyfunctionalized substrates was published by Yoshinao et al. [8]. Aqueous-phase hydrodeoxygenation of low-molecular-weight biomass oxygenates over heterogeneous Ni catalyst was studied by Jahromi and Agblevor $[9,10]$.

However, if aqueous conditions are applied, aldaric acids form equilibrium between the acid and lactone. The carboxyl group lactonizes by condensation with the $\mathrm{C} 4$ or $\mathrm{C} 5$ hydroxyl group, yielding 1,4- or 1,5- lactone. The lactone formation is accelerated by heating and in the presence of strong acids. It was reported that 1,4-lactone is more stable compared to 1,5-lactone, which is readily hydrolyzed in aqueous solution [5]. Lactone formation could be avoided by avoiding aqueous conditions or by protection of free carboxylic acids by esterification. Selective removal of hydroxyl groups can proceed when carboxylic groups are protected. If aldaric acids are converted into esters or lactones, both forms of aldaric acids could be used in condensation polymerization to produce hydroxylated nylons, as presented by Chen [11].

Selective hydrodeoxygenation of $\mathrm{C}-\mathrm{X}$ bonds ( $\mathrm{X}$ presents $\mathrm{O}, \mathrm{S}$, or $\mathrm{N}$ atom) is a highly desirable reaction, not only in biomass conversion $[12,13]$ but also in the petroleum industry for producing platform chemicals and industrially important chemicals, or to reduce sulphur content [14]. A comprehensive study was done on the catalytic hydrodeoxygenation of aliphatic and aromatic compounds by many researchers $[15,16]$. However, selective removal of particular functional groups is still a challenging process, especially because of various reactivity of each functional group and their mutual influence [17]. As presented by Boussie et al. [17], the reactivity of $-\mathrm{OH}$ groups is different depending on $\alpha$ - or $\beta$-position on the aldaric acids. $\beta$-OH groups, placed on $\mathrm{C} 3$ and $\mathrm{C} 4$ positions on glucaric acid, is expected to have higher reactivity than $\alpha-\mathrm{OH}$ groups placed on $\mathrm{C} 2$ and $\mathrm{C} 5$ positions. For that reason, hydrohalic acids are added for catalytic activation of all $\mathrm{C}-\mathrm{OH}$ bonds, by transformation into more reactive alkyl-halide intermediates [17]. Removing all -OH groups results in adipic acid. The highest yield of adipic acid was reached when $\mathrm{HBr}$ is added to the reaction mixture and acetic acid is used as a solvent.

Conversion, selectivity, and yield are strongly dependent on catalyst choice and reaction conditions. The most typical approach for HDO is a combination of an acid and a noble or transition metal catalyst. Presence of $\mathrm{Ru}$, Ir, or Rh metals can easily cause $\mathrm{C}-\mathrm{C}$ dissociation, while $\mathrm{Pd}$ and $\mathrm{Pt}$ are reported to be quite inactive for $\mathrm{C}-\mathrm{C}$ cleavage, also at high temperatures $[8,18]$. Normally, a combination of noble metal and group 6 or 7 metals are used, since they are responsible for $\mathrm{H}_{2}$ 
dissociation and C-O cleavage, respectively [8]. Metals are usually finely dispersed on acidic supports, which promote $\mathrm{C}-\mathrm{O}$ bond cleavage.

In our previous studies, the HDO of various functional groups on the C6 chain was studied [19] in order to establish a detailed microkinetic model. Based on previous studies, reaction conditions for presented research were estimated. The HDO of $\mathrm{C} 6$ aldaric acid (particularly mucic acid used in our study) over 10 different metal catalysts on neutral or acidic support was performed in this work in order to pin-point the most active catalyst for selective conversion of mucic acid. Initially, commercially available NiMo catalysts on $\mathrm{Al}_{2} \mathrm{O}_{3}$ support were tested, as it is the most well-known and commonly used hydrogenation and hydrotreatment catalyst in industrial applications. $\mathrm{NiMo} / \gamma-\mathrm{Al}_{2} \mathrm{O}_{3}$ catalyst was thoroughly tested for its activity of oxygen functional group removal from terminal and secondary positions of linear C6 backbone $[19,20]$ and lactonisation of levulinic acid [21]. NiMo catalyst was selected due to its proved HDO activity and low price, although the alumina support can transform into oxy-hydroxide ( $\mathrm{AlOOH}$ or trihydroxide $\left.\left(\mathrm{Al}(\mathrm{OH})_{3}\right)\right)$ in aqueous conditions [22]. However, the aim of the presented study is to investigate the influence of monometallic noble and transition metals on different supports on the HDO of mucic acid, a bio-based precursor for several important chemicals for the polymer industry.

Firstly, two experiments were performed with the selected catalyst at temperatures of $200{ }^{\circ} \mathrm{C}$ and $225^{\circ} \mathrm{C}$. Furthermore, conventional $\mathrm{HDO}$ catalysts with noble and transitional metals $(\mathrm{Ru}, \mathrm{Pt}, \mathrm{Rh}, \mathrm{Ni}$, $\mathrm{NiMo})$ on various supports $\left(\mathrm{C}, \mathrm{SiO}_{2}, \mathrm{Al}_{2} \mathrm{O}_{3}\right)$ were selected to be tested. Furthermore, the detail reaction pathway of mucic acid HDO was developed based on detected intermediates and products. The influence of catalyst type and reaction temperature on the conversion and product distribution was studied.

\section{Results and Discussion}

\subsection{Catalyst Characterization}

$\mathrm{N}_{2}$ physisorption analyses by BET (Brunauer-Emmett-Teller) method were performed for all fresh catalysts in order to determine specific surface area $\left(A_{\mathrm{BET}}\right)$, pore volume $(V \mathrm{p})$, and average pore width $(D p)$. Results are collected in Table 1 . Metal loading was $5 \mathrm{wt} \%$ for all catalysts except for NiMo on alumina, where metal loading for $\mathrm{Ni}$ and Mo was 3 and $15 \mathrm{wt} \%$, respectively. The highest surface area when $\mathrm{C}$ was used as a support is in line with expectations. Among all the catalysts, $\mathrm{Pt} / \mathrm{C}$ showed the highest specific surface area and $\mathrm{Pt} / \gamma-\mathrm{Al}_{2} \mathrm{O}_{3}$ the lowest. All metal catalysts on $\mathrm{SiO}_{2}$ support have similar surface areas (137-154 $\left.\mathrm{m}^{2} \mathrm{~g}^{-1}\right)$. The same trend in the size distribution was observed for pore volume - the highest value (twice higher compared to the others) was determined for $\mathrm{Pt} / \mathrm{C}$ and the lowest for the $\mathrm{Pt} / \gamma-\mathrm{Al}_{2} \mathrm{O}_{3}$, which was comparable to the $\mathrm{NiMo} / \gamma-\mathrm{Al}_{2} \mathrm{O}_{3}$. The highest pore width was determined for silica-supported catalysts $(17.1 \pm 1.6 \mathrm{~nm})$ followed by alumina-supported materials (around $9.5 \mathrm{~nm}$ ), and the lowest was reported for catalysts on C support (3.2 $\pm 0.9 \mathrm{~nm})$. TEM images of two catalysts are reported in Supplementary Materials (Figures S11 and S12), while other SEM and TEM micrographs were already reported and discussed in detail elsewhere [23]. In all cases, the results show that commercial catalysts contain well dispersed metal clusters below $5 \mathrm{~nm}$ in size.

$\mathrm{CO}$ and $\mathrm{CO}_{2}$ TPD (temperature programmed desorption) analyses were done for 4 catalysts, where the highest expected activities were informed by the literature (e.g., $\mathrm{Ru} / \mathrm{C}, \mathrm{Rh} / \mathrm{C} ; \mathrm{Ru} / \mathrm{SiO}_{2}$, $\mathrm{Rh} / \mathrm{SiO}_{2}$ ). In Figure 1a, the CO responses from CO TPD are shown. The samples containing carbon as a support resulted in a large peak at $700^{\circ} \mathrm{C}$, while the samples based on silica did not. Rh samples showed several peaks below $350{ }^{\circ} \mathrm{C}$, with a mean desorption temperature of $196^{\circ} \mathrm{C}$ and $207^{\circ} \mathrm{C}$ for $\mathrm{Rh} / \mathrm{C}$ and $\mathrm{Rh} / \mathrm{SiO}_{2}$, respectively. The peak area associated with $\mathrm{Rh}$ is 3.1 times higher in the case of $\mathrm{Rh} / \mathrm{C}$ in comparison with $\mathrm{Rh} / \mathrm{SiO}_{2}$, while the specific surface area is 7 times higher for $\mathrm{Rh} / \mathrm{C}$. Results in this work show an agreement with the literature, where $\mathrm{CO}$ was reported to desorb from the $\mathrm{Rh}$ on graphene oxide at $80{ }^{\circ} \mathrm{C}$ [24] and at $247^{\circ} \mathrm{C}$ from $\mathrm{Rh}(111)$ [25].

Desorption of $\mathrm{CO}$ was not observed in the case of $\mathrm{Ru}$ samples in significant amounts at temperatures below $350{ }^{\circ} \mathrm{C}$. Large peaks should not be associated with $\mathrm{CO}$ desorption from $\mathrm{Ru}$ 
metal (previously observed at much lower temperatures of $117^{\circ} \mathrm{C}$ and $167^{\circ} \mathrm{C}$ ), but rather with decarboxylation of carbonaceous support [26,27].

Table 1. Results from BET analyses.

\begin{tabular}{|c|c|c|c|c|}
\hline Catalyst & $\begin{array}{c}\text { Metal Loading } \\
\quad(w t \%)\end{array}$ & $\begin{array}{c}S_{\mathrm{BET}} \\
\left(\mathrm{m}^{2} \mathrm{~g}^{-1}\right)\end{array}$ & $\begin{array}{c}V p \\
\left(\mathrm{~cm}^{3} \mathrm{~g}^{-1}\right)\end{array}$ & $\begin{array}{c}D p \\
(\mathrm{~nm})\end{array}$ \\
\hline $\mathrm{NiMo} / \gamma-\mathrm{Al}_{2} \mathrm{O}_{3}$ & $3 / 15^{1}$ & 123 & 0.29 & 9.6 \\
\hline $\mathrm{Pt} / \gamma-\mathrm{Al}_{2} \mathrm{O}_{3}$ & 5 & 97 & 0.23 & 9.5 \\
\hline $\mathrm{Rh} / \mathrm{SiO}_{2}$ & 5 & 147 & 0.58 & 15.5 \\
\hline $\mathrm{Pt} / \mathrm{SiO}_{2}$ & 5 & 144 & 0.67 & 18.7 \\
\hline $\mathrm{Ni} / \mathrm{SiO}_{2}$ & 5 & 137 & 0.58 & 16.6 \\
\hline $\mathrm{Ru} / \mathrm{SiO}_{2}$ & 5 & 154 & 0.66 & 17.1 \\
\hline $\mathrm{Ru} / \mathrm{C}$ & 5 & 745 & 0.74 & 4.0 \\
\hline $\mathrm{Ni} / \mathrm{C}$ & 5 & 1017 & 0.57 & 2.6 \\
\hline $\mathrm{Pt} / \mathrm{C}$ & 5 & 1275 & 1.22 & 3.7 \\
\hline $\mathrm{Rh} / \mathrm{C}$ & 5 & 1032 & 0.58 & 2.3 \\
\hline
\end{tabular}

${ }^{1}$ The $3 w t \%$ of Ni and $15 w t \%$ of Mo.

However, we also observed desorption of $\mathrm{CO}_{2}$ in a CO-TPD experiment in the case of Ru catalysts at temperatures below $400{ }^{\circ} \mathrm{C}$ (Figure $1 \mathrm{~b}$ ). A comparison between $\mathrm{CO}_{2}$ response from CO-TPD and $\mathrm{CO}_{2}$ response from $\mathrm{CO}_{2}$-TPD showed higher desorbed amounts of $\mathrm{CO}_{2}$ in the case of CO-TPD at several temperatures. This can be explained by the oxidation of $\mathrm{CO}$ with $\mathrm{H}_{2} \mathrm{O}$ impurities on $\mathrm{Ru}$ surface, since supported $\mathrm{Ru}$ is a WGS (water gas shift) catalyst with TOF (turnover frequency) roughly 10 times higher than the supported Rh catalyst [28]. Sulphided $\mathrm{NiMo} / \gamma-\mathrm{Al}_{2} \mathrm{O}_{3}$ catalyst was extensively characterized and tested on other HDO systems in our previous works $[19,21,29]$.
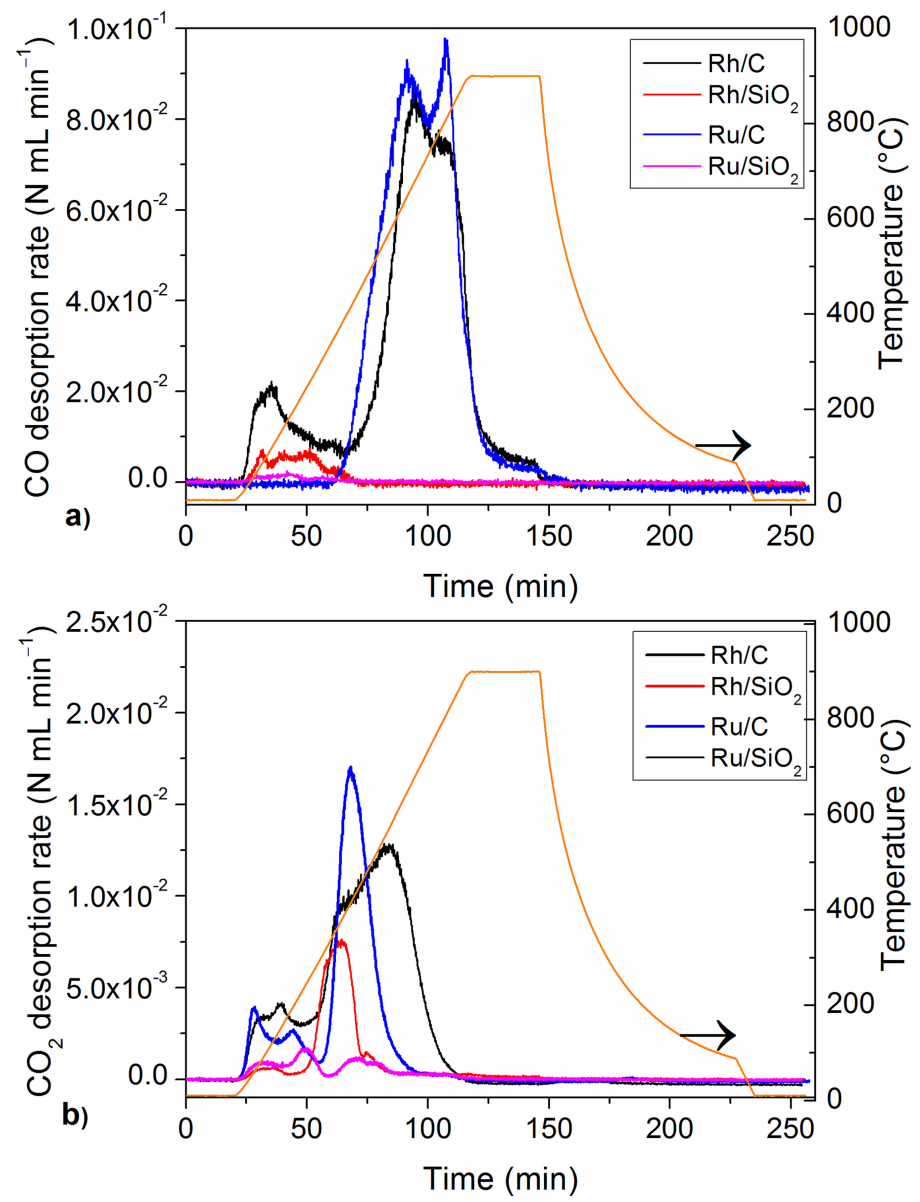

Figure 1. $\mathrm{CO}(\mathbf{a})$ and $\mathrm{CO}_{2}(\mathbf{b})$ desorption rates of the supported Ru- and Rh-based catalysts during CO-TPD. 
Data corresponded to the surface density of metallic sites $\left(N_{\mathrm{AS}}\right)$ and showed no significant difference between different metals on supports. Obtained concentrations of active sites were in the relatively narrow range between $2.5 \times 10^{-5}$ and $1.1 \times 10^{-4} \mathrm{~mol} \mathrm{~g}^{-1}$ for all commercial catalysts used in this work, therefore their availability and relatively similar dispersion are not expected to be the most critical or deterministic criteria of the catalyst performance. However, this information is crucial for the upcoming micro-kinetic modelling concentration of acidic sites determined by $\mathrm{NH}_{3}$-TPD analysis, which showed similar values as for metal sites, with concentrations in the range between $4.1 \times 10^{-5}$ and $1.2 \times 10^{-3} \mathrm{~mol} \mathrm{~g}^{-1}$. The highest concentration of acidic active sites was determined on alumina support, as it can be seen in Figure S13. Detailed characterization results are available in Supplementary Materials (Tables S1-S2).

\subsection{Reaction Pathway Development: Bulk Phase Reactions}

The proposed reaction pathway network of mucic acid hydrotreatment is presented in Figure 2. The reaction pathway is subdivided into the bulk (non-catalytic) and heterogeneously catalyzed part. The upper part of the reaction scheme presents non-catalytic transformations in the bulk liquid phase, while the scheme of heterogeneous transformations is extensive due to the series of parallel and consecutive reactions and several intermediates and products observed during the HDO. Intermediates and products follow the deoxygenation method (upside down) and the decrease of chain length (from left to right side). Furanic compounds are marked in orange and completely deoxygenated products in blue. Further oligomerization (regarding the detected products, please see Supplementary Materials Tables S3-S5) is not presented on the scheme to retain its clarity. Different colors present lumping groups, in which the compounds are grouped for determination of their selectivity.

In the absence of a catalyst, mucic-1,4-lactone (2) is formed, which is common in aqueous media [30]. Equilibrium between mucic acid (1) and its lactone (2) was established, since the lactonization of carboxyl group mucic acid with the $-\mathrm{OH}$ group on $\mathrm{C} 4$ or $\mathrm{C} 5$ position can form 1,4- or 1,5-lactone, respectively. It is well known from the literature that 1,4-lactone is more stable compared to 1,5-lactone, which was reported to readily re-hydrolyze [30]. 1,4-lactone was detected already at room temperature, which proves immediate formation of lactone from mucic acid in the presence of water. The established equilibrium between mucic acid and its 1,4-lactone is marked with a blue arrow in Figure 2. The formation of lactone was confirmed by LC-MS (liquid chromatography-mass spectrometry) analysis, where its specific mass fragments (parent ion with molar mass of $196 \mathrm{~g} \mathrm{~mol}^{-1}$ ) were detected (Figure S2). Under inert atmosphere only, the above-mentioned lactone was detected besides mucic acid, while under high $\mathrm{H}_{2}$ pressure ( $>5 \mathrm{MPa}$ ), formation of galactonic acid was promoted (4), marked with an orange arrow. Minor formation of galacturonic acid (3) was noticed at the highest temperature without a catalyst, $175{ }^{\circ} \mathrm{C}$. Galactonic and galacturonic acid were both confirmed by the LC-MS (Figures S2 and S4).

Before the reaction temperature reached the set value, mucic acid was not completely dissolved in water. The solubility of mucic acid and 1,4-lactone increases with temperature, resulting in the gradual concentration increase in the liquid phase. As presented by Brown et al. [31], glucaric acid can form 2 different monolactones that can both further convert into the mucic-(1,4:6,3)-dilactone. In the pH-neutral media, 1,4-lactone forms more slowly than 1,5-lactone. Elevated temperature and neutral media favored the formation of mucic-(1,4:6,3)-dilactone, which was not detected at lower temperatures. Even though higher temperature was applied, dilactone was not detected in our experiments. Homogeneous transformation was confirmed using LC-MS analysis, where specific fragmentation patterns confirmed lactone, galacturonic, and gluconic acid formation according to specific molar masses. Detailed LC-MS results, including chromatograms and MS spectra, are presented in Supplementary Materials (Figures S2-S4). 


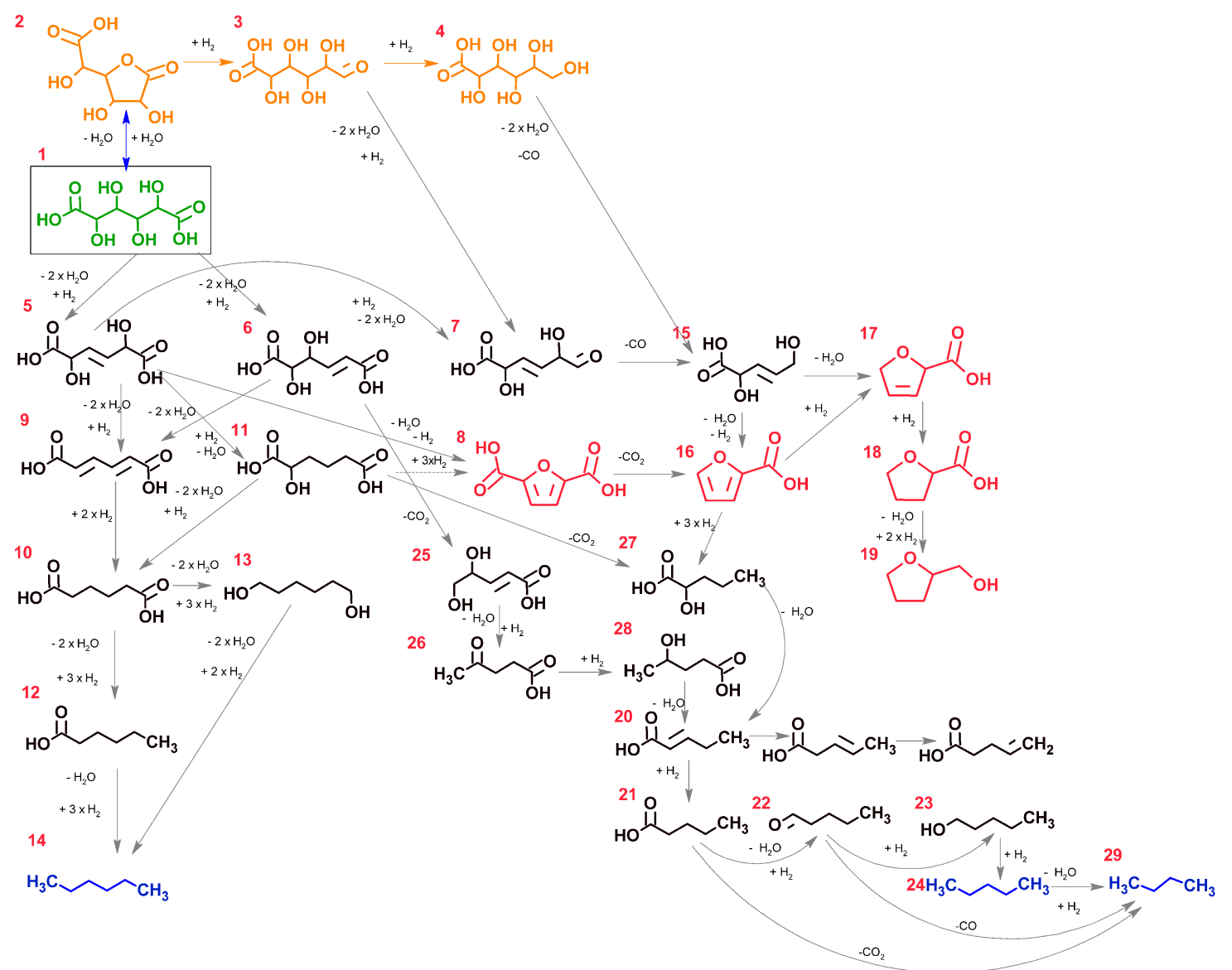

Figure 2. Proposed reaction pathway development based on HPLC, LC-MS, and GC-MS analyses.

\subsection{Reaction Pathway Development: Catalytic Reactions}

HDO of mucic acid was catalyzed by different metal catalysts on neutral or acidic supports. Partially or completely deoxygenated products were detected by GC-MS (gas chromatography mass spectrometry). The proposed reaction scheme is presented in Figure $2 . \mathrm{H}_{2} \mathrm{O}$ was eliminated in the first step either directly from mucic acid (1) or from galacturonic (3) and galactonic acid (4), resulting in C6 diols with one or two terminal carboxylic groups (compounds marked as 5 and 6 in Figure 2). A pair of water molecules can be eliminated from mucic acid, specifically from the C2-C3 or C3-C4 position [17], which determines further formation of intermediates. Compounds (5) and (6) are further deoxygenated and hydrogenated, resulting in adipic acid, detected by GC-MS and HPLC (high-performance liquid chromatography) analysis. Adipic acid was gradually deoxygenated to the 1,6-hexanediol and furthermore to the final alkane-hexane. If HDO proceeds only on one terminal carboxylic group, hexanoic acid is formed. However, gradual HDO of each terminal carboxylic group leads to the same final deoxygenated alkane-hexane. During water molecule elimination from the oxygenated compound $\left(-\mathrm{H}_{2} \mathrm{O}\right)$, the double bond is usually formed, readily hydrogenated $\left(+\mathrm{H}_{2}\right)$ to the single bond. For better review of the reaction pathway, this step is sometimes omitted (e.g., from 1,6-hexanediol to the hexane, from the pentanol to the pentane, etc.).

However, formation of shorter chain products is linked to the decarboxylation or decarbonylation of carboxylic functional group. In the case where two molecules of water were eliminated from the C2-C3 position (of 6) and further decarboxylation (of 25) proceeded with HDO, levulinic acid (26) was formed. Double bonds were hydrogenated simultaneously. Further hydrogenation of the carbonyl group $(\mathrm{C}=\mathrm{O})$ resulted in hydroxyl pentanoic acid (21), detected by GC-MS (gas chromatography-mass spectrometry). An additional deoxygenation led to the pentanoic acid, subsequently deoxygenated to the pentane through pentanal and 1-pentanol formation. 
As mentioned before, water elimination from mucic acid (or galacturonic acid and galactonic acid) usually proceeds at the $\mathrm{C} 3$ and $\mathrm{C} 4$ positions, due to higher reactivity of $\beta-\mathrm{OH}$ groups [17] resulting in the products (5), (7), and (15). Further dehydroxylation of (5) led to the same product as water elimination from galacturonic acid (7). Furanic compounds, such as furancarboxylic acid and tetrahydrofurfuryl alcohol, were formed due to water elimination with subsequent cyclization. With hydrogenation of furanic compounds, firstly double bonds were saturated $(16 \rightarrow 17 \rightarrow 18)$; furthermore, the furan ring opens, resulting in 2-hydroxy pentanoic acid (27). The 2-hydroxypentanoic acid was deoxygenated by a known procedure, where firstly the - $\mathrm{OH}$ group on the $\mathrm{C} 2$ position was deoxygenated to the different forms of pentenoic acid, shifting the double bond (20). The double bond was hydrogenated, resulting in pentanoic acid (21). All further HDO steps of pentanoic acid are already mentioned above. When complete HDO was reached, only alkanes were formed (pentane, butane). Gradual deoxygenation follows a similar pathway as was previously presented in the linear model compound HDO studies [19,20]. Partially-deoxygenated C3 compounds were detected in small amounts. At high temperatures, $\mathrm{C}-\mathrm{C}$ bond cleavage was observed, which resulted in partially deoxygenated compounds of $\mathrm{C} 3-\mathrm{C} 5$ chain length. Furan-2,5-dicarboxylic acid is a possible intermediate mentioned in the literature [32]; however, it was not detected in the experiment, therefore its formation is marked with a dashed arrow on the reaction scheme. The first publication regarding the conversion of mucic acid into furan dicarboxylic acid was published in 1876 by Fitting and Heinzelmann. Many of the detected compounds are of special interest to the chemical industry, especially in polymer production as bio-based monomers. The most important detected chemicals are adipic acid and furan-based products. Detected adipic acid is one of the most important platform chemicals, mostly used for Nylon 6,6 production. Furoic acid is known as a flavoring agent in the food industry and it can also be used for optic technologies. Other carboxylic acids and polyols are important chemicals in the polymer industry [33].

\subsection{The Influence of Catalyst Type and Reaction Conditions on the HDO Selectivity of Mucic Acid}

Ten different commercially available materials consisting of noble or transition metals on $\mathrm{C}, \mathrm{Al}_{2} \mathrm{O}_{3}$, or $\mathrm{SiO}_{2}$ supports (various acidity) were tested in this catalyst screening study. Noble metals are known for activation of oxygenated compounds on metal sites $[8,34]$.

The complexity of the system demands a combination of different analytic methods to detect all formed products presented in Figure 2 and collected in the Table 2. The final products of hydrodeoxygenation are alkanes, which are non-soluble in water and could form a separate (organic) liquid phase. Therefore, the final reaction mixture was always extracted with diethyl ether, derived from (esterified with three methyl silyl esters), and analyzed by, GC-MS. From combined results of both analytic methods (Table 3), a table with products detected by HPLC and GC-MS was formed. Catalysts affected the formation rate of products and their distribution.

Complete conversion of mucic acid was reached over $\mathrm{NiMo} / \gamma-\mathrm{Al}_{2} \mathrm{O}_{3}$ at $200{ }^{\circ} \mathrm{C}$ or higher and no lactones were detected in the liquid phase. Not all deoxygenated products with low polarity remain in aqueous phase, and the most probably form a separate (organic) liquid phase, therefore they were only identified after the extraction of final products in diethyl ether. Many short-chain products were detected after derivatization and GC-MS analysis (Figure S1), revealing that $\mathrm{C}-\mathrm{C}$ bond cleavage proceeded alongside HDO. Mucic acid and products (2-4) could not be detected by GC-MS due to the geometrically-hindered derivatization and high boiling points of corresponding products (boiling points above $350^{\circ} \mathrm{C}$ ).

Table 3 presents a distribution of intermediates and products in the aqueous phase and diethyl ether extract and Figure 3 the conversion of mucic acid over $\mathrm{NiMo} / \gamma-\mathrm{Al}_{2} \mathrm{O}_{3}$ catalyst at 200 and $225^{\circ} \mathrm{C}$. In the latter, the highest concentrations were detected for tetrahydro-furfuryl alcohol $\left(36.0 \%\right.$ at $\left.200{ }^{\circ} \mathrm{C}\right)$ and adipic acid $\left(32.3 \%\right.$ at $\left.225{ }^{\circ} \mathrm{C}\right)$. Notable amounts of 2-hydroxypentanoic acid (5.6-7.4\%), levulinic acid (5.0-5.5\%), furoic acid (6.3-25.4\%), 2-pentenoic acid (1.8-3.6\%), and 3-methyl-2-hydroxypentanoic 
acid (3.0-5.8\%) were detected as well. Other products were present in lower concentrations (below 3\%). Some of the compounds were detected in aqueous phase (by HPLC) and in the extract (GC-MS).

Table 2. List of compounds with molecular formula, molar mass, and retention times according to the HPLC and GC-MS analysis.

\begin{tabular}{|c|c|c|c|c|c|}
\hline Prod No. & Name of Compound & $\begin{array}{l}\text { Molecular } \\
\text { Formula }\end{array}$ & $\begin{array}{l}\text { Molar Mass } \\
\left(\mathrm{g} \mathrm{mol}^{-1}\right)\end{array}$ & $\begin{array}{l}\text { Ret. Time (HPLC) } \\
\text { (min) }\end{array}$ & $\begin{array}{l}\text { Ret. Time (GC-MS) } \\
\text { (min) }\end{array}$ \\
\hline 1 & Mucic acid & $\mathrm{C}_{6} \mathrm{H}_{10} \mathrm{O}_{8}$ & 210 & 2.3 & - \\
\hline 2 & Mucic-1,4-lactoneMucic-3,6-lactone & $\mathrm{C}_{6} \mathrm{H}_{8} \mathrm{O}_{7}$ & 192 & 2.7 & 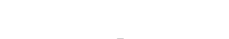 \\
\hline 3 & Galacturonic acid & $\mathrm{C}_{6} \mathrm{H}_{10} \mathrm{O}_{7}$ & 194 & 2.1 & - \\
\hline 4 & Galactonic acid & $\mathrm{C}_{6} \mathrm{H}_{12} \mathrm{O}_{7}$ & 196 & 1.9 & - \\
\hline 5 & 2,5-dihydroxy dihexenoic acid & $\mathrm{C}_{6} \mathrm{H}_{8} \mathrm{O}_{6}$ & 176 & - & - \\
\hline 8 & Furandicarboxylic acid & $\mathrm{C}_{6} \mathrm{H}_{4} \mathrm{O}_{5}$ & 156 & 9.5 & - \\
\hline 9 & Muconic acid & $\mathrm{C}_{6} \mathrm{H}_{6} \mathrm{O}_{4}$ & 142 & 10.3 & - \\
\hline 10 & Adipic acid & $\mathrm{C}_{6} \mathrm{H}_{10} \mathrm{O}_{4}$ & 146 & 9.9 & 18.4 \\
\hline 11 & 2-hydroxy hexanoic acid & $\mathrm{C}_{6} \mathrm{H}_{10} \mathrm{O}_{5}$ & 162 & 11.3 & 17.2 \\
\hline 12 & Hexanoic acid & $\mathrm{C}_{6} \mathrm{H}_{12} \mathrm{O}_{2}$ & 116 & 12.7 & 15.7 \\
\hline 13 & 1,6-Hexanediol & $\mathrm{C}_{6} \mathrm{H}_{14} \mathrm{O}_{2}$ & 118 & - & - \\
\hline 18 & Tetrahydro-2-furancarboxylic acid & $\mathrm{C}_{5} \mathrm{H}_{8} \mathrm{O}_{3}$ & 116 & 6.3 & - \\
\hline 19 & Tetrahydro-2-furfuryl alcohol & $\mathrm{C}_{5} \mathrm{H}_{10} \mathrm{O}_{2}$ & 102 & 11.3 & 15.6 \\
\hline 20 & 2-Pentenoic acid & $\mathrm{C}_{5} \mathrm{H}_{8} \mathrm{O}_{2}$ & 100 & - & 13.8 \\
\hline 21 & Pentanoic acid & $\mathrm{C}_{5} \mathrm{H}_{10} \mathrm{O}_{2}$ & 102 & - & 14.5 \\
\hline 22 & Pentanal & $\mathrm{C}_{5} \mathrm{H}_{10} \mathrm{O}$ & 86 & - & - \\
\hline 23 & 1-Pentanol & $\mathrm{C}_{5} \mathrm{H}_{12} \mathrm{O}$ & 88 & - & - \\
\hline 24 & Pentane & $\mathrm{C}_{5} \mathrm{H}_{12}$ & 72 & - & - \\
\hline 25 & 1,2-dihydroxy pentenoic acid & $\mathrm{C}_{5} \mathrm{H}_{8} \mathrm{O}_{4}$ & 132 & - & - \\
\hline 26 & Levulinic acid & $\mathrm{C}_{5} \mathrm{H}_{8} \mathrm{O}_{3}$ & 116 & 5.6 & 15.45 \\
\hline 27 & 2-hydroxy pentanoic acid & $\mathrm{C}_{5} \mathrm{H}_{10} \mathrm{O}_{3}$ & 118 & - & 15.91 \\
\hline 28 & 4-hydroxy pentenoic acid & $\mathrm{C}_{5} \mathrm{H}_{10} \mathrm{O}_{3}$ & 118 & - & 15.84 \\
\hline 29 & Butane & $\mathrm{C}_{4} \mathrm{H}_{10}$ & 58 & - & - \\
\hline
\end{tabular}

Table 3. Products distribution in the aqueous and extracted phase over $\mathrm{NiMo} / \gamma-\mathrm{Al}_{2} \mathrm{O}_{3}$ catalyst.

\begin{tabular}{|c|c|c|c|c|}
\hline \multirow{2}{*}{ Name } & \multicolumn{2}{|c|}{ Molar Fraction in the Diethyl Ether Extract ${ }^{1}$} & \multicolumn{2}{|c|}{ Yields in the Reaction Mixture ${ }^{2}$} \\
\hline & $\begin{array}{c}T=200{ }^{\circ} \mathrm{C} \\
(\mathrm{mol} \%)\end{array}$ & $\begin{array}{c}T=225{ }^{\circ} \mathrm{C} \\
(\mathrm{mol} \%)\end{array}$ & $\begin{array}{c}T=200{ }^{\circ} \mathrm{C} \\
(\mathrm{mol} \%)\end{array}$ & $\begin{array}{c}T=225^{\circ} \mathrm{C} \\
(\mathrm{mol} \%)\end{array}$ \\
\hline Tetrahydro-2-furfuryl alcohol & 36.0 & 12.4 & 10.1 & - \\
\hline Adipic acid & 24.3 & 32.3 & 4.25 & 4.33 \\
\hline 2-Hydroxypentanoic acid & 7.4 & 5.6 & - & - \\
\hline Levulinic acid & 5.5 & 5.0 & 1.12 & 3.08 \\
\hline 2-Furoic acid & 6.3 & 25.4 & 0.14 & 0.39 \\
\hline 2-Pentenoic acid & 3.6 & 1.8 & - & - \\
\hline 2-Hydroxyhexanoic acid & 0.8 & 2.1 & 1.48 & 1.08 \\
\hline 4-Pentenoic acid & 3.2 & 2.4 & - & - \\
\hline 2-Methylpropanoic acid & 2.2 & - & - & - \\
\hline Hexanoic acid & 1.6 & 1.3 & - & - \\
\hline 2-Methyl-1-butanol & 1.0 & 1.0 & - & - \\
\hline Butyric acid & 2.8 & 2.8 & - & - \\
\hline Propanoic acid & 0.9 & 1.2 & - & - \\
\hline 2-Butene-1,4-diol & 0.7 & - & - & - \\
\hline 4-Hydroxypentanoic acid & 0.8 & 0.9 & - & - \\
\hline 3-Methyl-2-hydroxypentanoic acid & 3.0 & 5.8 & - & - \\
\hline
\end{tabular}

${ }^{1}$ Identified by GC-MS and quantified using GC-FID; ${ }^{2}$ identified by LC-MS and quantified by HPLC-UV/VIS.

Based on the HPLC results, the selectivity towards the adipic acid in the final reaction mixture was $4.25 \%$ at the temperature of $200{ }^{\circ} \mathrm{C}$ and $4.33 \%$ at $225{ }^{\circ} \mathrm{C}$. Selectivity to THF-alcohol (Tetrahydro-2-furfuryl alcohol) was $10.1 \%$ at the temperature of $200{ }^{\circ} \mathrm{C}$, but due to its very low UV absorbance, it could not be detected in reaction mixture at $225^{\circ} \mathrm{C}$. The ratio between products with 
C6 chain length and chain length the same or lower than C5 increases with reaction temperature. The reason for the observed behavior could be temperature-dependent selectivity, which is, however, opposite to the results obtained in the literature, where higher temperatures led to the furanic compounds formation over Rh catalyst in $\mathrm{MeOH}$ [7].

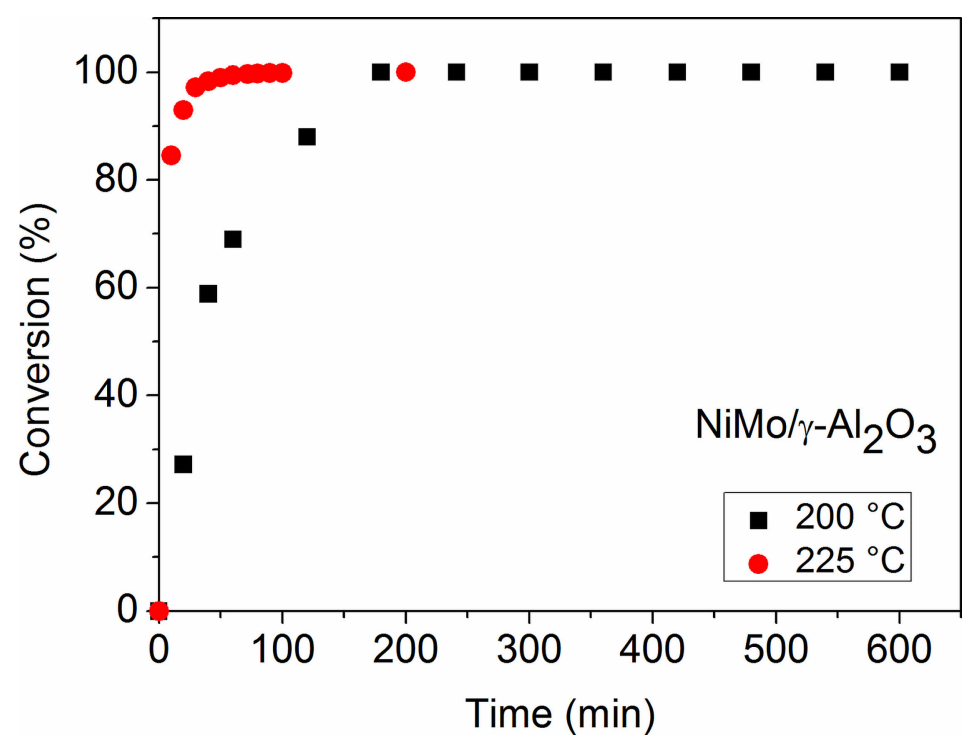

Figure 3. Conversion of mucic acid during $\mathrm{HDO}$ over sulphided $\mathrm{NiMo} / \gamma-\mathrm{Al}_{2} \mathrm{O}_{3}$ catalyst at 200 and $225^{\circ} \mathrm{C}$.

Even though conversion of mucic acid was complete and no lactone was detected, the main product was galactonic acid. Besides galactonic acid, many partially deoxygenated products were formed. From the aspect of selectivity towards $\mathrm{C} 6$ dicarboxylic acids and diols, $\mathrm{C}-\mathrm{C}$ bond cleavage (i.e., decarboxylation) is not desired, therefore the catalysts with higher activity were chosen and temperature below $200^{\circ} \mathrm{C}$ was applied to aim the selectivity towards the desired products. Dicarboxylic acids and polyols are desirable products, especially for the polymer industry. Successful catalyst reusability tests for $\mathrm{NiMo} / \gamma-\mathrm{Al}_{2} \mathrm{O}_{3}$ are described in the supplementary data (Figures $\mathrm{S} 14$ and S15).

Besides NiMo on alumina, the catalyst often used for HDO of biomass compounds is $\mathrm{Pt} / \mathrm{Al}_{2} \mathrm{O}_{3}[12,35,36]$. Since sulphided NiMo on alumina showed sufficient stability under aqueous conditions for short reactions, we decided to test the $\mathrm{Pt} / \mathrm{Al}_{2} \mathrm{O}_{3}$ catalyst for mucic acid hydrotreatment. $\mathrm{Pt}$ on alumina showed lower mucic acid conversion at $175^{\circ} \mathrm{C}$ compared to NiMo on alumina, which was similar or higher at lower temperatures $\left(125-150^{\circ} \mathrm{C}\right)$. The $70 \%$ mucic acid conversion was achieved over $\mathrm{Pt} / \mathrm{Al}_{2} \mathrm{O}_{3}$, while cumulative conversion of mucic acid and its lactones (the latter is formed by non-catalytic dehydration) was $60 \%$. Results showed that Pt has lower HDO activity compared to NiMo at temperatures $>175^{\circ} \mathrm{C}$ and higher at temperatures $<150^{\circ} \mathrm{C}$, while the summarized conversions of mucic acid and lactone are alike. There is no significant change in conversion between the lowest or the highest tested temperature over $\mathrm{Pt} / \mathrm{Al}_{2} \mathrm{O}_{3}$, while $\mathrm{NiMo} / \gamma-\mathrm{Al}_{2} \mathrm{O}_{3}$ showed high temperature dependence. Regarding the products detected by the HPLC, 2-hydroxyhexanoic acid was detected besides lactone at all temperatures at approximately the same yield of $4.9 \mathrm{~mol} \%$. An acidic support (alumina) promotes the formation of two different lactones (1,4- and 3,6-lactone), which is in accordance with the literature $[30,31,37]$.

However, the ratio between lactone and mucic acid is slightly affected by the temperature; lactone formation is faster than mucic acid hydrodeoxygenation at higher temperatures. The same trend was noticed under non-catalytic conditions in inert atmosphere. As mentioned before, under aqueous conditions the $\gamma-\mathrm{Al}_{2} \mathrm{O}_{3}$ support could be transformed into alumina oxy-hydroxide, but a favorable combination of NiMo or Pt metals on $\mathrm{Al}_{2} \mathrm{O}_{3}$ support could have beneficial effects on supported catalyst activity and stability in an aqueous environment [38]. However; the deactivation 
of the alumina-supported catalyst was tested, where recycled $\mathrm{NiMo} / \gamma-\mathrm{Al}_{2} \mathrm{O}_{3}$ catalyst was used in a second run. Results (Figures S14 and S15) showed negligible differences in the conversion of mucic acid and product distribution. Considering the BET results, alumina supported catalysts showed the lowest surface area per gram of catalyst. The lowest surface area and pore volume was determined for Pt catalyst, since the pore width was larger for alumina-supported catalysts compared to carbon-supported. Our results are in line with the literature, where many authors showed that pore size diameter has an effect on mass transfer in catalyst pores, and therefore on catalyst activity and product selectivity $[39,40]$.

The influence of catalyst type on the time-resolved conversion of mucic acid is presented in Figure 4, while Figure 5 shows a cumulative conversion of mucic acid and its lactone. Conversions for all other experiments are collected in Supplementary Materials (Figures S5 and S6). Cumulative conversion $\left(X_{\mathrm{ML}}\right)$ of mucic acid and its lactone was calculated according to Equation (1).

$$
X_{\mathrm{ML}}=\frac{C_{0 \mathrm{M}}-\left(C_{\mathrm{M}}+C_{\mathrm{L}}\right)}{C_{0 \mathrm{M}}}
$$

where $C_{0 \mathrm{M}}$ represents the initial concentration of mucic acid, while $C_{\mathrm{M}}$ represents concentrations of mucic acid and $C_{\mathrm{L}}$ of its lactone at every given time. $\mathrm{Ru}, \mathrm{Rh}, \mathrm{Ni}$, and $\mathrm{Pt}$ on $\mathrm{SiO}_{2}$ support were tested for HDO of mucic acid and the results showed the following metal activity: $\mathrm{Rh}>\mathrm{Ru}>\mathrm{Ni}>\mathrm{Pt}$. Rh and $\mathrm{Ru}$ are the most active metals, since both mucic acid and its lactone conversion were higher than $80 \%$. A slightly lower conversion was reached with $\mathrm{Ru}$ at $125^{\circ} \mathrm{C}$. Results are quite expected and in accordance with the literature, where high activity of $\mathrm{Ru}$ and $\mathrm{Rh}$ for $\mathrm{C}-\mathrm{O}$ and $\mathrm{C}-\mathrm{C}$ bond cleavage was reported [12,41]. Levulinic acid was detected at $150{ }^{\circ} \mathrm{C}$ over $\mathrm{Ru} / \mathrm{SiO}_{2}$ in minor concentrations (yield of $1 \mathrm{~mol} \%$ ). Yield to 2-hydroxy hexanoic acid decreased with increasing temperature (from $8.0 \mathrm{~mol} \%$ to $4.5 \mathrm{~mol} \%$ ). The same trend of decreasing yield to 2-hydroxy hexanoic was noticed when $\mathrm{Rh} / \mathrm{SiO}_{2}$ was used.
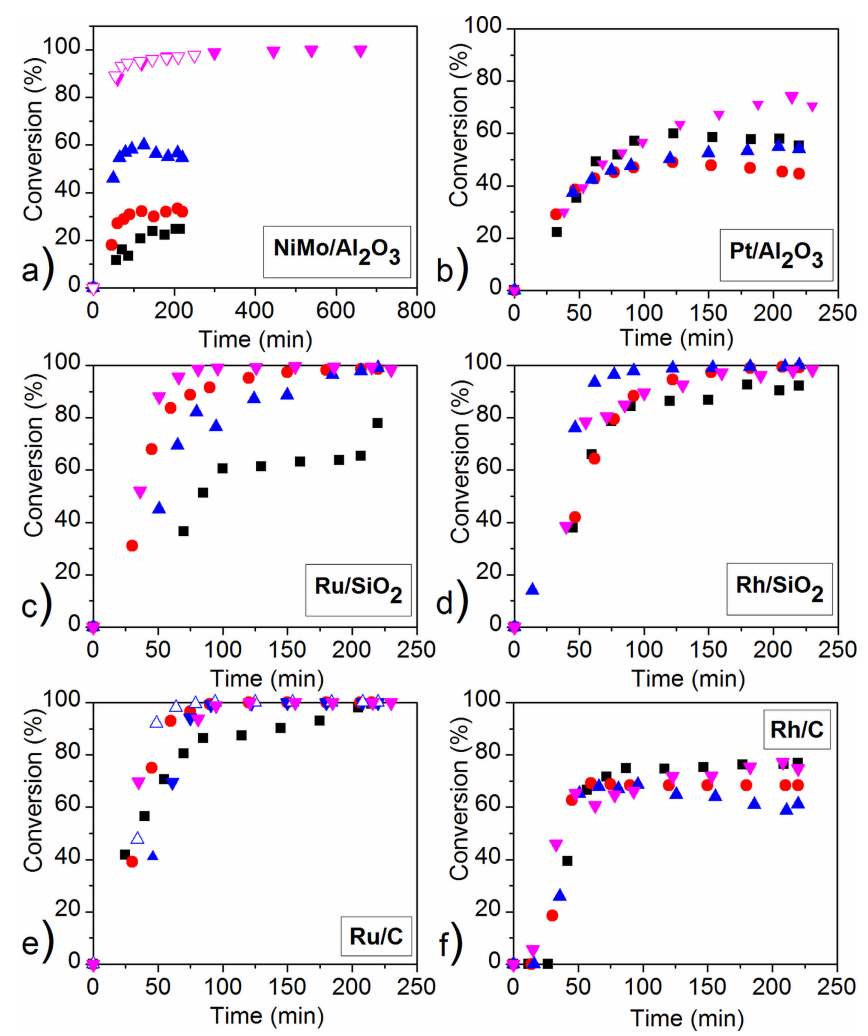

Figure 4. Conversion of mucic acid over (a) $\mathrm{NiMo} / \gamma-\mathrm{Al}_{2} \mathrm{O}_{3}$, (b) $\mathrm{Pt} / \mathrm{Al}_{2} \mathrm{O}_{3}$, (c) $\mathrm{Ru} / \mathrm{SiO}_{2}$, (d) $\mathrm{Rh} / \mathrm{SiO}_{2}$, (e) $\mathrm{Ru} / \mathrm{C}$, and (f) $\mathrm{Rh} / \mathrm{C}$ at the $\mathrm{T}=125^{\circ} \mathrm{C}, \bullet \mathrm{T}=135^{\circ} \mathrm{C}, \boldsymbol{\Delta} T=150^{\circ} \mathrm{C}$, and $\boldsymbol{\nabla} \mathrm{T}=175^{\circ} \mathrm{C}$. Empty symbols represent results for repeated experiments. 

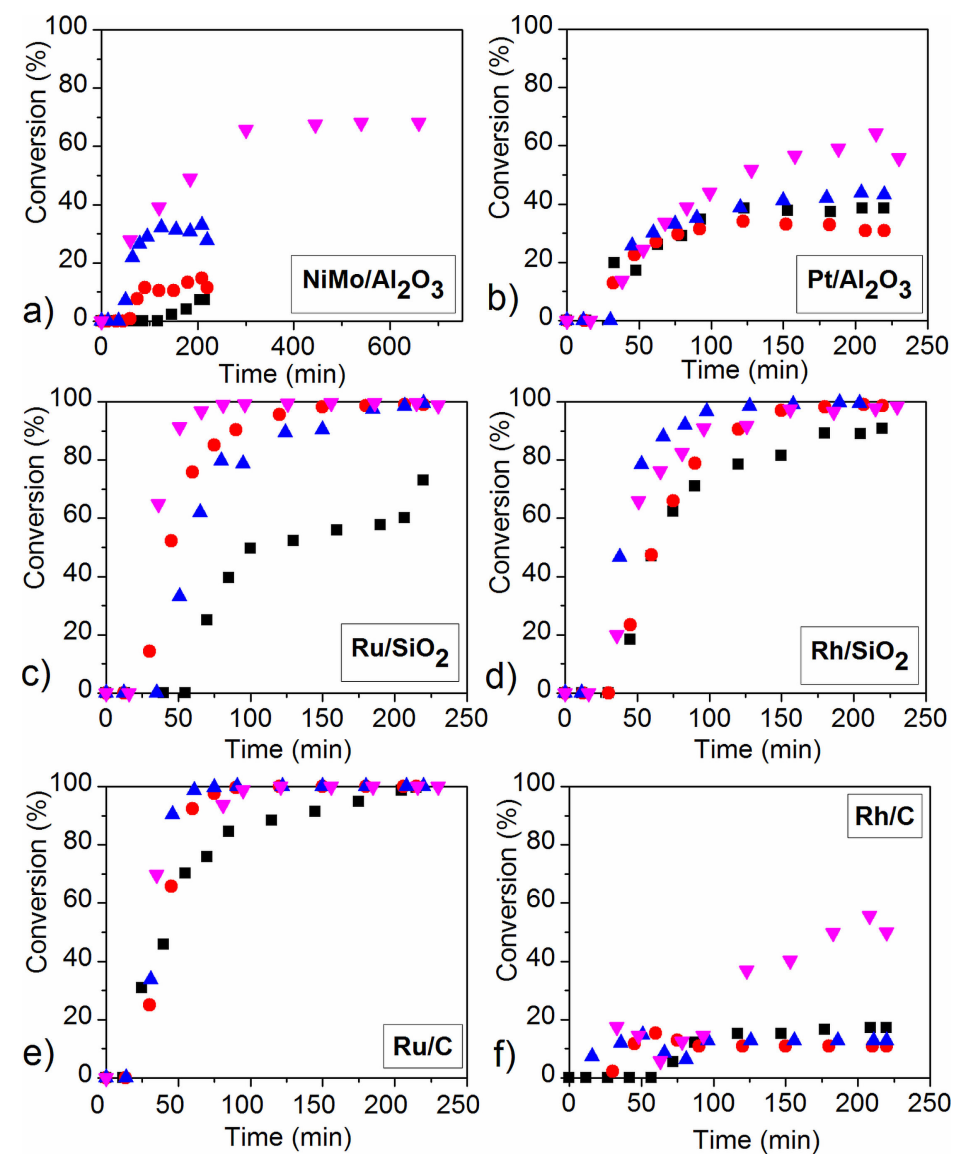

Figure 5. Summarized conversion of mucic acid and its lactone over (a) $\mathrm{NiMo} / \mathrm{Al}_{2} \mathrm{O}_{3},(\mathbf{b}) \mathrm{Pt} / \mathrm{Al}_{2} \mathrm{O}_{3}$, (c) $\mathrm{Ru} / \mathrm{SiO}_{2}$, (d) $\mathrm{Rh} / \mathrm{SiO}_{2}$, (e) $\mathrm{Ru} / \mathrm{C}$, and (f) $\mathrm{Rh} / \mathrm{C}$ at $\boldsymbol{\square}=125^{\circ} \mathrm{C}, \bullet \mathrm{T}=135^{\circ} \mathrm{C}, \boldsymbol{\Delta} \mathrm{T}=150{ }^{\circ} \mathrm{C}$, and $\nabla T=175^{\circ} \mathrm{C}$.

At the highest temperature $\left(175^{\circ} \mathrm{C}\right)$ the conversion for both $\mathrm{Ru}$ and $\mathrm{Rh}$ was around $100 \%$, but almost no products were detected in the final reaction mixture by HPLC. The possible explanation is formation of the second (nonpolar) phase, where all products with low polarity were dissolved. The water from the final product was removed by vacuum distillation and the solid residue was derived by esterification and analyzed by GCMS. The components reported in Tables S3-S5 and their main groups are presented in Figure 6. Among all the tested catalysts, Rh showed the highest selectivity to the furanic and cyclic compounds at the lowest tested temperature. It is worth mentioning that the highest concentration $(38.6 \%$, in the esterified mixture of products, where water was removed by rotary evaporation) of tetrahydro-2H-pyran-4-ol was formed at the reaction temperature of $125^{\circ} \mathrm{C}$ over the $\mathrm{Rh} / \mathrm{C}$ catalyst. The amount of it decreased from $38.6 \%$ to $3.9 \%$ with increasing reaction temperature from $125^{\circ} \mathrm{C}$ to $175^{\circ} \mathrm{C}$, respectively. However, the conversion of mucic acid over $\mathrm{Rh} / \mathrm{C}$ was very low. In contrast, the amount of the tetrahydro furfuryl alcohol increased with the increasing temperature, from $21.7 \%$ to $31.0 \%$ at temperatures from $125^{\circ} \mathrm{C}$ to $175{ }^{\circ} \mathrm{C}$, respectively. A similar trend was noticed for tetrahydro-2H-pyran-4-ol, but in considerably lower concentrations than the $\mathrm{Rh} / \mathrm{SiO}_{2}$ catalyst. However, the concentration of furfuryl alcohol showed no significant difference between the lowest and the highest temperature when silica-supported Rh was used.

$\mathrm{Ni}$ and $\mathrm{Pt}$ on $\mathrm{SiO}_{2}$ support resulted in significantly lower conversion; specifically, it was between $20 \%$ and $60 \%$ for both metals. The summarized conversion of mucic acid and lactone was even lower, with $\mathrm{Pt} / \mathrm{SiO}_{2}$ showing a minor conversion. In general, $\mathrm{Pt} / \mathrm{SiO}_{2}$ mucic acid only achieved equilibrium with its own lactone, whereas the ratio was similar to the non-catalytic conditions. The 2-Hydroxyhexanoic acid was determined by HPLC to be the product with the highest yield ( $7.7 \mathrm{~mol} \%$ with $\mathrm{Ni} / \mathrm{SiO}_{2}$ ). The established equilibrium between mucic acid and lactone can change 
during the reaction, resulting in an apparent drop of the conversion, especially for less active catalysts (e.g., $\mathrm{Pt} / \mathrm{SiO}_{2}$ ). Some unknown compounds were detected in product mixtures (analyzed by HPLC), which were expected to be compounds considered in extraction mixtures of $\mathrm{NiMo} / \gamma-\mathrm{Al}_{2} \mathrm{O}_{3}$, and were confirmed with further GCMS analysis of the solid products after water removal by vacuum distillation and further derivatization (Figure 6 and Table S5). Pt-supported carbon and silica showed very similar results. At the lowest temperatures, mainly shorter, partially-deoxygenated compounds and furanic compounds were formed, while at the highest temperature, the concentration of oligomers increased. The highest formation of oligomers was noticed over alumina-supported $\mathrm{Pt}$; however, the conversion was, in this case, lower compared to other more active metals ( $\mathrm{Rh}, \mathrm{Ru}$ ). Comparing both alumina-supported catalysts, NiMo showed higher selectivity to partially deoxygenated linear products with chain lengths $<\mathrm{C} 6$ and much lower selectivity to the oligomers compared to Pt catalyst.

$\mathrm{Ru}, \mathrm{Rh}, \mathrm{Ni}$, and Pt metal screening over neutral C-support again showed high activity for the $\mathrm{Ru}$ catalyst, as the conversion exceeded $85 \%$ at all tested temperatures, while other metals never reached $80 \%$ conversion. Rh was nearly non-active on $\mathrm{C}$ although it was the most active on $\mathrm{SiO}_{2}$ support. In contrast, $\mathrm{Ni}$ showed better activity on $\mathrm{C}$, as it did on the $\mathrm{SiO}_{2}$ support. A significantly higher conversion (near $100 \%$ ) was reached at the temperature of $175^{\circ} \mathrm{C}$. However, the summarized conversions of mucic acid and lactone reached only $60 \%$ for the Rh catalyst and $85 \%$ for the Ni catalyst with $\mathrm{C}$ support. The Pt catalyst showed better activity on the $\mathrm{C}$ support than on the $\mathrm{SiO}_{2}$ support, especially the summarized conversion of mucic acid and its lactone.
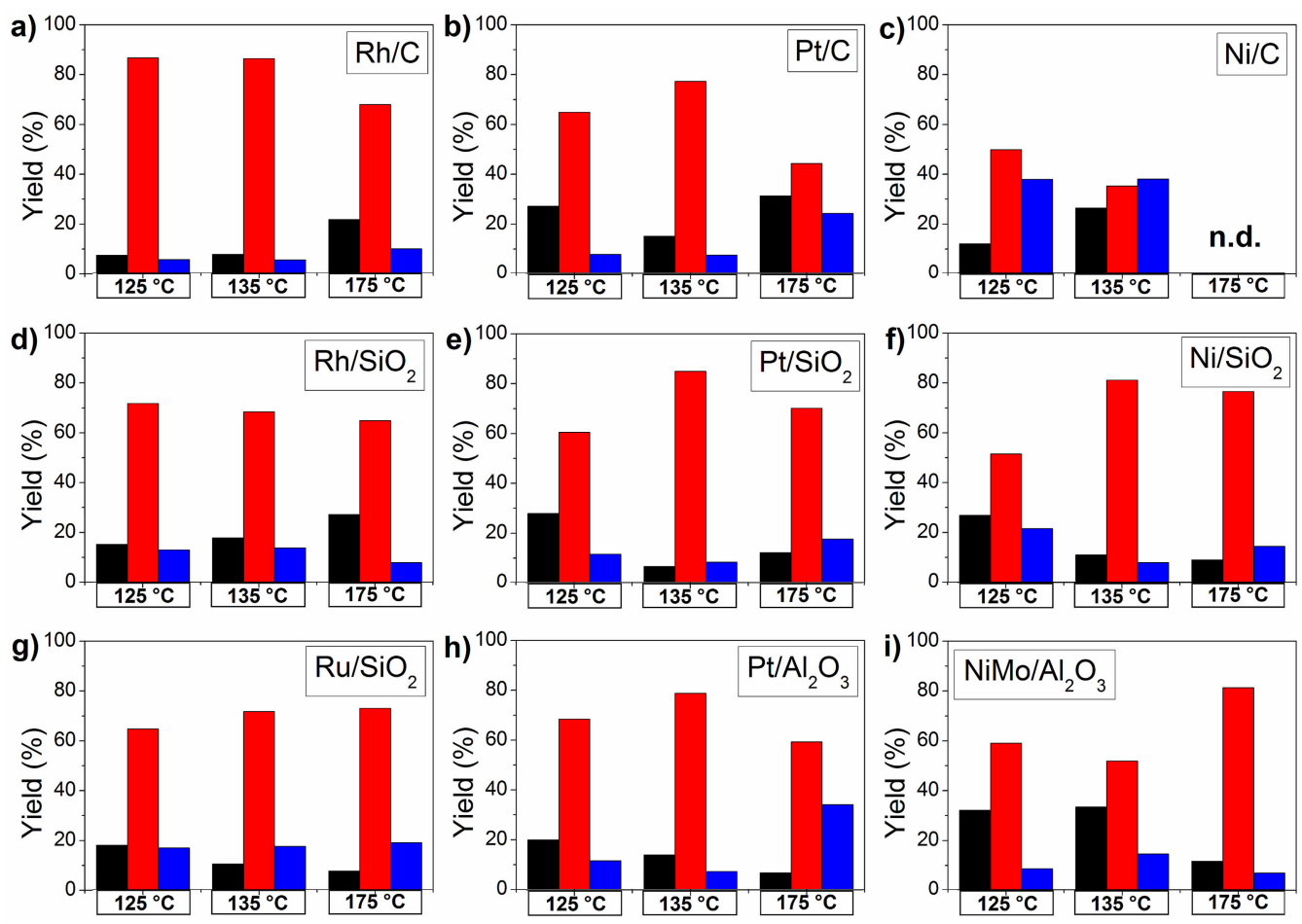

Figure 6. Selectivity to representative group of products over each catalyst: (a) $\mathrm{Rh} / \mathrm{C},(\mathbf{b}) \mathrm{Pt} / \mathrm{C},(\mathbf{c}) \mathrm{Ni} / \mathrm{C}$, (d) $\mathrm{Rh} / \mathrm{SiO}_{2}$, (e) $\mathrm{Pt} / \mathrm{SiO}_{2}$, (f) $\mathrm{Ni} / \mathrm{SiO}_{2}$, (g) $\mathrm{Ru} / \mathrm{SiO}_{2}$, (h) $\mathrm{Pt} / \mathrm{Al}_{2} \mathrm{O}_{3}$, and (i) $\mathrm{NiMo} / \mathrm{Al}_{2} \mathrm{O}_{3}$. Black: partially or completely deoxygenated short chain products (chain length < C6). Red: cyclic products (mostly furanic compounds). Blue: long chain (oligomerized) products (chain length $>\mathrm{C} 8$ ).

Even though mucic acid conversion over $\mathrm{Rh} / \mathrm{C}$ was quite high, it can be seen that summarized conversion of mucic acid and lactone was very low, especially at low temperatures, which is quite unexpected. The lack of acidic active sites on $\mathrm{Rh} / \mathrm{C}$ can lead to a low yield of HDO products. Interactions between noble metals and the acidic support could give better HDO activity for the catalyst [42]. However, $\mathrm{Ru} / \mathrm{C}$ has 1.7 times wider pores than $\mathrm{Rh} / \mathrm{C}$. Wider pores are more accessible for molecules to be adsorbed in. Considering the BET results, the wider pores of $\mathrm{Ru} / \mathrm{C}$ could lead to higher 
conversion of mucic acid and catalytic transformation of oxygenated molecules due to better mass transfer of molecules [39]. Similar results obtained by $\mathrm{SiO}_{2} 2$-hydroxyl hexanoic acid was detected when noble metals on $\mathrm{C}$ support were used. Moreover tetrahydro-2-furoic acid was also detected. Selectivity to shorter chain products is enhanced by using the catalyst with narrow pore width [39]. BET results (Table 1) showed that all carbon-supported catalysts have pores with diameter $<4 \mathrm{~nm}$. Among all the tested metals, Ni showed the highest selectivity to adipic acid. Nevertheless, the yield of adipic acid not under any tested reaction conditions exceeded $5 \mathrm{~mol} \%$.

In general, from obtained results the most active catalysts for $\mathrm{HDO}$ of mucic acid in water phase at low temperatures were $\mathrm{Ru} / \mathrm{C}, \mathrm{Ru} / \mathrm{SiO}_{2}$, and $\mathrm{Rh} / \mathrm{SiO}_{2}$ catalysts. As a support, $\mathrm{SiO}_{2}$ showed the best performance at tested reaction conditions ( $T$ and $P$ ), and although it is known to be stable in the acidic aqueous phase, some studies reported a decrease of activity after its testing in boiling water for $24 \mathrm{~h} \mathrm{[43].} \mathrm{Carbon-supported} \mathrm{Ni} \mathrm{enhanced} \mathrm{the} \mathrm{oligomerization} \mathrm{of} \mathrm{the} \mathrm{lower} \mathrm{chain} \mathrm{products}$ and results at a temperature of $135^{\circ} \mathrm{C}$ were very similar to the results obtained at $175^{\circ} \mathrm{C}$ with the carbon-supported Pt catalyst. Formation of oligomer compounds, especially completely deoxygenated ones, showed high activity for carbon-supported $\mathrm{Ni}$ and $\mathrm{Pt}$ for deoxygenation processes. Results obtained for silica-supported Ru showed no significant difference in the selectivity at the lowest and the highest temperature. Moreover, almost the same selectivity to each group of products were obtained for carbon and silica-supported Ru at $135^{\circ} \mathrm{C}(7.8 \%, 73.0 \%$, and $19.1 \%$ over carbon-supported $\mathrm{Ru}$ and $10.6 \%, 71.8 \%$, and $17.7 \%$ over silica-supported $\mathrm{Ru}$ for lower chain products, furans, and oligomers, respectively).

Catalysts doped with transition metal presented better hydrothermal stability than the undoped support. [44] The presence of acidic active sites $\left(\mathrm{Al}_{2} \mathrm{O}_{3}\right)$ or highly active noble metals were crucial for $\mathrm{HDO}$ to proceed. However, $\mathrm{NiMo} / \gamma-\mathrm{Al}_{2} \mathrm{O}_{3}$ showed good activity and stability at higher temperatures, even in the aqueous phase above $175^{\circ} \mathrm{C}$ for a short treatment (less than $5 \mathrm{~h}$ ) $[44,45]$. The reusability test was performed over alumina-supported NiMo catalyst under presented reaction conditions at $175^{\circ} \mathrm{C}$. The fresh catalyst was used for the first experiment, and recycled for the second experiment. Results were very similar with a conversion of $89 \%$ and $90 \%$ under fresh and recycled catalysts, respectively. Detailed results are collected in the Supplementary Materials (Figures S14 and S15). The lowest activity for the selected catalytic system was reached with all three tested Pt catalysts (on alumina, silica, and carbon support), showing normal HDO levels but high hydrogenation activity, in accordance with the literature [43]. Experiments performed only over supports showed similar results to those obtained under noncatalytic system (Figures S8-S10). Only formation of different lactones was detected.

\section{Materials and Methods}

\subsection{Catalyst Characterization}

Each of the commercially available catalysts (Table 1) was milled into the particles with diameters under $100 \mu \mathrm{m}$ before catalytic activity testing. The catalyst composition is given according to the data provided by the suppliers (Sigma Aldrich, St. Louis, MO, USA, and Riogen, NJ, USA).

The Braunauer-Emmett-Teller method (BET) was used for the evaluation of the specific surface area $\left(A_{\mathrm{BET}}\right)$, using an ASAP 2020 instrument for $\mathrm{N}_{2}$-physisorption (Micrometrics, Norcross, GA, USA). Metalic surface site densities were measured using a Micrometrics AutoChem II Chemisorption Analyzer (Micrometrics, Norcross, GA, USA) by the CO TPD experiment. Analyses were carried out in the temperature range of $10-900{ }^{\circ} \mathrm{C}$. The molecule desorbing was monitored on-line by a quadrupole mass spectrometer ThermoStar TM GSD $301 \mathrm{~T}$ (Pfeiffer Vacuum GmbH, Aßlar, Germany). Prior to analysis, each catalyst (about $100 \mathrm{mg}$ ) was reduced by heating it up to $300{ }^{\circ} \mathrm{C}$ in the flow of $5 \% \mathrm{H}_{2} / \mathrm{Ar}$ with a heating rate of $10^{\circ} \mathrm{C} \mathrm{min}-1$ and by keeping this temperature constant for $10 \mathrm{~min}$. Subsequently the sample was cooled down in a flow of inert gas (helium; $50 \mathrm{~mL} \mathrm{~min}^{-1}$ ) to $10{ }^{\circ} \mathrm{C}$ and saturated in a flow of gas mixture containing $5 \mathrm{vol} \% \mathrm{CO}$ in He. The sample was then purged to remove weakly adsorbed species in He for $2 \mathrm{~h}$. Desorption was carried out in the flow of $\mathrm{He}\left(20 \mathrm{~mL} \mathrm{~min}^{-1}\right)$ with a 
linear heating rate of $8.9^{\circ} \mathrm{C} \mathrm{min}^{-1}$ from $10{ }^{\circ} \mathrm{C}$ to $900{ }^{\circ} \mathrm{C}$ and kept for $30 \mathrm{~min}$ at $900{ }^{\circ} \mathrm{C}$. The total time of the TPD analysis was $150 \mathrm{~min}$. During CO-TPD, concentration profiles were collected for $\mathrm{CO}$ and $\mathrm{CO}_{2}$ by following the $m / z=12$ and 44 mass-to-charge signal ratio, respectively. Mass spectrometer was calibrated daily with the calibration mixtures.

\subsection{Hydrotreatment Experiments}

Catalytic hydrotreatment experiments were performed in a six parallel batch high-pressure autoclave system (Amar Equipment Pvt. Ltd., Mumbai, India), each consisting of a vessel with $250 \mathrm{~mL}$ volume with the inner diameter of $67 \mathrm{~mm}$ and the height of $80 \mathrm{~mm}$. Each autoclave was equipped with a magnetically driven Rushton turbine impeller, diameter of $30 \mathrm{~mm}$, placed $14 \mathrm{~mm}$ above the autoclave bottom. Before reaction the autoclave was filled with $120 \mathrm{~g}$ of solvent (distilled water), $0.17 \mathrm{wt} \%$ of a reactant (Mucic acid, $97 \mathrm{wt} \%$, Sigma Aldrich), and $0.42 \mathrm{wt} \%$ of catalyst. Catalysts used for catalytic experiments were commercially available solid metal catalysts on different supports, specifically $\mathrm{NiMo} / \gamma-\mathrm{Al}_{2} \mathrm{O}_{3}(3(\mathrm{Ni}) / 15(\mathrm{Mo}) \mathrm{wt} \%$ loading pellets for industrial use in hydrotreating units sulphided off-site in the laboratory Totsucat process Eure-cat (La Voulte-sur-Rhône, France) by the $\mathrm{H}_{2} \mathrm{~S} / \mathrm{H}_{2}$ sulphiding agents $\mathrm{Pt} / \gamma-\mathrm{Al}_{2} \mathrm{O}_{3}(5 \mathrm{wt} \% \mathrm{Pt}$ loading, powder, Sigma Aldrich, St. Louis, $\mathrm{MO}$, USA), $\mathrm{Ru} / \mathrm{SiO}_{2}$ (5 wt $\%$ Ru loading, powder, Riogen, NJ, USA), $\mathrm{Rh} / \mathrm{SiO}_{2}$ (5 wt $\%$ Rh loading, powder, Riogen, NJ, USA), $\mathrm{Pt} / \mathrm{SiO}_{2}$ (5 wt\% $\mathrm{Pt}$ loading, powder, Riogen, NJ, USA), $\mathrm{Ni} / \mathrm{SiO}_{2}$ ( $5 \mathrm{wt} \% \mathrm{Ni}$ loading, powder, Riogen, NJ, USA), Ru/C (5 wt \% Ru loading, powder, Sigma Aldrich, St. Louis, MO, USA), $\mathrm{Ni} / \mathrm{C}$ (5 wt \% Ni loading, powder, Sigma Aldrich, St. Louis, MO, USA), Pt/C (5 wt\% Pt loading, powder, Sigma Aldrich, St. Louis, MO, USA), and Rh/C (5 wt \% Rh loading, powder, Riogen, NJ, USA). Reactants, solvents, and catalysts were weighed on the autoclave vessel, placed in the housing and sealed. The heating belt was attached to the autoclave. Before pressurizing the reactor with hydrogen (5.0, Messer, Bad Soden am Taunus, Germany), each autoclave was flushed with inert gas twice $\left(\mathrm{N}_{2} ; 5.0\right.$, Messer, Bad Soden am Taunus, Germany). All experiments were performed in a batch regime with an agitation speed of $600 \mathrm{~min}^{-1}$, which ensures the gaseous phase aspiration and complete dispersion of the catalyst particles. The temperature profile started at room temperature and then increased to the desired temperature with a heating ramp of $5 \mathrm{~K} \mathrm{~min}^{-1}$ by keeping the reaction at the plateau temperature for three hours.

Table 4. List of experiments using mucic acid as a reactant, dissolved in distilled water. Experiments were performed under high pressure of inert gas $\left(\mathrm{N}_{2}\right)$ or hydrogen $\left(\mathrm{H}_{2}\right)$.

\begin{tabular}{cccccc}
\hline Experiment Number & Catalyst & $\begin{array}{c}\boldsymbol{T} \\
\left({ }^{\circ} \mathbf{C}\right)\end{array}$ & $\begin{array}{c}\boldsymbol{P}_{\mathbf{H} 2} \\
\mathbf{( M P a})\end{array}$ & $\begin{array}{c}\boldsymbol{P}_{\mathbf{N} 2} \\
(\mathbf{M P a})\end{array}$ & $\begin{array}{c}\text { Reactant/Catalyst Ratio } \\
(/)\end{array}$ \\
\hline 1 & $\mathrm{NiMo} / \gamma-\mathrm{Al}_{2} \mathrm{O}_{3}$ & 125 & 5 & 0 & 0.4 \\
2 & $\mathrm{NiMo} / \gamma-\mathrm{Al}_{2} \mathrm{O}_{3}$ & 135 & 5 & 0 & 0.4 \\
3 & $\mathrm{NiMo} / \gamma-\mathrm{Al}_{2} \mathrm{O}_{3}$ & 150 & 5 & 0 & 0.4 \\
4 & $\mathrm{NiMo} / \gamma-\mathrm{Al}_{2} \mathrm{O}_{3}$ & 175 & 5 & 0 & 0.4 \\
5 & $\mathrm{NiMo} / \gamma-\mathrm{Al}_{2} \mathrm{O}_{3}$ & 200 & 5 & 0 & 0.4 \\
6 & $\mathrm{NiMo} / \gamma-\mathrm{Al}_{2} \mathrm{O}_{3}$ & 225 & 5 & 0 & 0.4 \\
7 & $\mathrm{Pt} / \gamma-\mathrm{Al}_{2} \mathrm{O}_{3}$ & 125 & 5 & 0 & 0.4 \\
8 & $\mathrm{Pt} / \gamma-\mathrm{Al}_{2} \mathrm{O}_{3}$ & 135 & 5 & 0 & 0.4 \\
9 & $\mathrm{Pt} / \gamma-\mathrm{Al}_{2} \mathrm{O}_{3}$ & 150 & 5 & 0 & 0.4 \\
10 & $\mathrm{Pt} / \gamma-\mathrm{Al}_{2} \mathrm{O}_{3}$ & 175 & 5 & 0 & 0.4 \\
11 & $\mathrm{Rh} / \mathrm{SiO}_{2}$ & 125 & 5 & 0 & 0.4 \\
12 & $\mathrm{Rh} / \mathrm{SiO}_{2}$ & 135 & 5 & 0 & 0.4 \\
13 & $\mathrm{Rh} / \mathrm{SiO}_{2}$ & 150 & 5 & 0 & 0.4 \\
14 & $\mathrm{Rh} / \mathrm{SiO}_{2}$ & 175 & 5 & 0 & 0.4 \\
15 & $\mathrm{Pt} / \mathrm{SiO}_{2}$ & 125 & 5 & 0 & 0.4 \\
16 & $\mathrm{Pt} / \mathrm{SiO}_{2}$ & 135 & 5 & 0 & 0.4 \\
17 & $\mathrm{Pt} / \mathrm{SiO}_{2}$ & 150 & 5 & 0 & 0.4 \\
18 & $\mathrm{Pt} / \mathrm{SiO}_{2}$ & 175 & 5 & 0 & 0.4 \\
19 & $\mathrm{Ni} / \mathrm{SiO}_{2}$ & 125 & 5 & 0 & 0.4 \\
20 & $\mathrm{Ni} / \mathrm{SiO}_{2}$ & 135 & 5 & 0 & \\
\hline
\end{tabular}


Table 4. Cont.

\begin{tabular}{|c|c|c|c|c|c|}
\hline Experiment Number & Catalyst & $\begin{array}{c}T \\
\left({ }^{\circ} \mathrm{C}\right) \\
\end{array}$ & $\begin{array}{c}P_{\mathrm{H} 2} \\
(\mathrm{MPa})\end{array}$ & $\begin{array}{c}P_{\mathrm{N} 2} \\
(\mathrm{MPa})\end{array}$ & $\begin{array}{c}\text { Reactant/Catalyst Ratio } \\
(/)\end{array}$ \\
\hline 21 & $\mathrm{Ni} / \mathrm{SiO}_{2}$ & 150 & 5 & 0 & 0.4 \\
\hline 22 & $\mathrm{Ni} / \mathrm{SiO}_{2}$ & 175 & 5 & 0 & 0.4 \\
\hline 23 & $\mathrm{Ru} / \mathrm{SiO}_{2}$ & 125 & 5 & 0 & 0.4 \\
\hline 24 & $\mathrm{Ru} / \mathrm{SiO}_{2}$ & 135 & 5 & 0 & 0.4 \\
\hline 25 & $\mathrm{Ru} / \mathrm{SiO}_{2}$ & 150 & 5 & 0 & 0.4 \\
\hline 26 & $\mathrm{Ru} / \mathrm{SiO}_{2}$ & 175 & 5 & 0 & 0.4 \\
\hline 27 & $\mathrm{Ru} / \mathrm{C}$ & 125 & 5 & 0 & 0.4 \\
\hline 28 & $\mathrm{Ru} / \mathrm{C}$ & 135 & 5 & 0 & 0.4 \\
\hline 29 & $\mathrm{Ru} / \mathrm{C}$ & 150 & 5 & 0 & 0.4 \\
\hline 30 & $\mathrm{Ru} / \mathrm{C}$ & 175 & 5 & 0 & 0.4 \\
\hline 31 & $\mathrm{Ni} / \mathrm{C}$ & 125 & 5 & 0 & 0.4 \\
\hline 32 & $\mathrm{Ni} / \mathrm{C}$ & 135 & 5 & 0 & 0.4 \\
\hline 33 & $\mathrm{Ni} / \mathrm{C}$ & 150 & 5 & 0 & 0.4 \\
\hline 34 & $\mathrm{Ni} / \mathrm{C}$ & 175 & 5 & 0 & 0.4 \\
\hline 35 & $\mathrm{Pt} / \mathrm{C}$ & 125 & 5 & 0 & 0.4 \\
\hline 36 & $\mathrm{Pt} / \mathrm{C}$ & 135 & 5 & 0 & 0.4 \\
\hline 37 & $\mathrm{Pt} / \mathrm{C}$ & 150 & 5 & 0 & 0.4 \\
\hline 38 & $\mathrm{Pt} / \mathrm{C}$ & 175 & 5 & 0 & 0.4 \\
\hline 39 & $\mathrm{Rh} / \mathrm{C}$ & 125 & 5 & 0 & 0.4 \\
\hline 40 & $\mathrm{Rh} / \mathrm{C}$ & 135 & 5 & 0 & 0.4 \\
\hline 41 & $\mathrm{Rh} / \mathrm{C}$ & 150 & 5 & 0 & 0.4 \\
\hline 42 & $\mathrm{Rh} / \mathrm{C}$ & 175 & 5 & 0 & 0.4 \\
\hline 43 & No cat. & 125 & 5 & 0 & - \\
\hline 44 & No cat. & 135 & 5 & 0 & - \\
\hline 45 & No cat. & 150 & 5 & 0 & - \\
\hline 46 & No cat. & 175 & 5 & 0 & - \\
\hline 47 & No cat. & 125 & 0 & 5 & - \\
\hline 48 & No cat. & 135 & 0 & 5 & - \\
\hline 49 & No cat. & 150 & 0 & 5 & - \\
\hline 50 & No cat. & 175 & 0 & 5 & - \\
\hline 51 & Carbon & 150 & 5 & 0 & 0.4 \\
\hline 52 & Silica & 150 & 5 & 0 & 0.4 \\
\hline 53 & Alumina & 150 & 5 & 0 & 0.4 \\
\hline
\end{tabular}

Liquid samples were collected during the reaction time. After three hours at the plateau temperature, the autoclave was rapidly cooled down, the gas phase was released, and the headspace was purged with inert gas $\left(\mathrm{N}_{2}\right)$ before opening the autoclave. All data about reaction conditions (time, set temperature, temperature in the autoclave, heater temperature, and pressure) were recorded automatically by SCADA system. Experimental conditions are summarized in Table 4. Mucic acid was used in all experiments as a reactant dissolved in water, as a solvent, and in hydrogen as a co-reactant in a gaseous phase, with initial pressure at room temperature set to $5 \mathrm{MPa}$.

\subsection{Analytic Methods}

Liquid samples were collected from the reactor vessel during the reaction. The initial sample was taken at room temperature right before the heater was turned on, the second was taken at half of the heating ramp temperature, the third at the final temperature, and then at 15 min intervals within the first hour after completion, and following this in $30 \mathrm{~min}$ intervals. Eleven liquid samples of $1 \mathrm{~mL}$ were taken during the experimental time. The samples were further prepared for analyses by different methods, namely high performance liquid chromatography (HPLC) or gas chromatography coupled with mass spectrometry (GC-MS). Analytical methods and sample preparations are reported in Figure 7 and Figure S7.

The collected liquid samples were directly analyzed by liquid chromatography (HPLC, Agilent

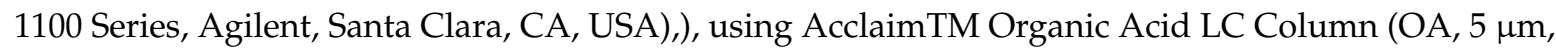
$12 \mathrm{~nm}, 4.0 \times 250 \mathrm{~mm}$, TermoFisher, Waltham, MA, USA). The injection volume of a sample was $20 \mu \mathrm{L}$. The gradient method was applied for the mobile phase, starting with the water phase $(2.5 \mathrm{mM}$ 
$\mathrm{H}_{2} \mathrm{SO}_{4}\left(98.0 \%\right.$, Sigma Aldrich, St. Luis, MO, USA) in $\mathrm{H}_{2} \mathrm{O}$, $\mathrm{pH}$ of 2.4) for 4 min. The organic phase (Acetonitrile, anhydrous, 99.8\%, Sigma Aldrich, St. Luis, MO, USA) was then gradually added to the final 9:1 volume ratio of organic to water phase, reached in $10 \mathrm{~min}$ and then kept constant for $11 \mathrm{~min}$, and after that in changed back to pure water phase in $2 \mathrm{~min}$ and kept for constant for a further $3 \mathrm{~min}$. The constant mobile phase flow of $1 \mathrm{~mL} \mathrm{~min}^{-1}$ was regulated by two binary pumps. Column temperature was kept at $30^{\circ} \mathrm{C}$. Reactants, intermediates, and products were detected by a UV detector in the range from 200 to $400 \mathrm{~nm}$. Quantification data were collected at the reference wavelength of $210 \mathrm{~nm}$ using a narrow slit. For unknown compounds, LC-MS (molecular mass spectrometer from Applied Biosystems, model 4000 Q TRAP MS/MS, coupled with liquid chromatography; HPLC-DAD, Agilent, 1100 Series, Agilent, Santa Clara, CA, USA) analysis was performed using the same column (AcclaimTM Organic Acid LC Column, TermoFisher, Waltham, MA, USA) with the same method; however, the $2.5 \mathrm{mM} \mathrm{H}_{2} \mathrm{SO}_{4}$ mobile phase was substituted with the $0.1 v / v \%$ trifluoro acetic acid (TFA, $\geq 99.0 \%$, Sigma Aldrich, St. Luis, MO, USA) because of MS analysis restrictions.

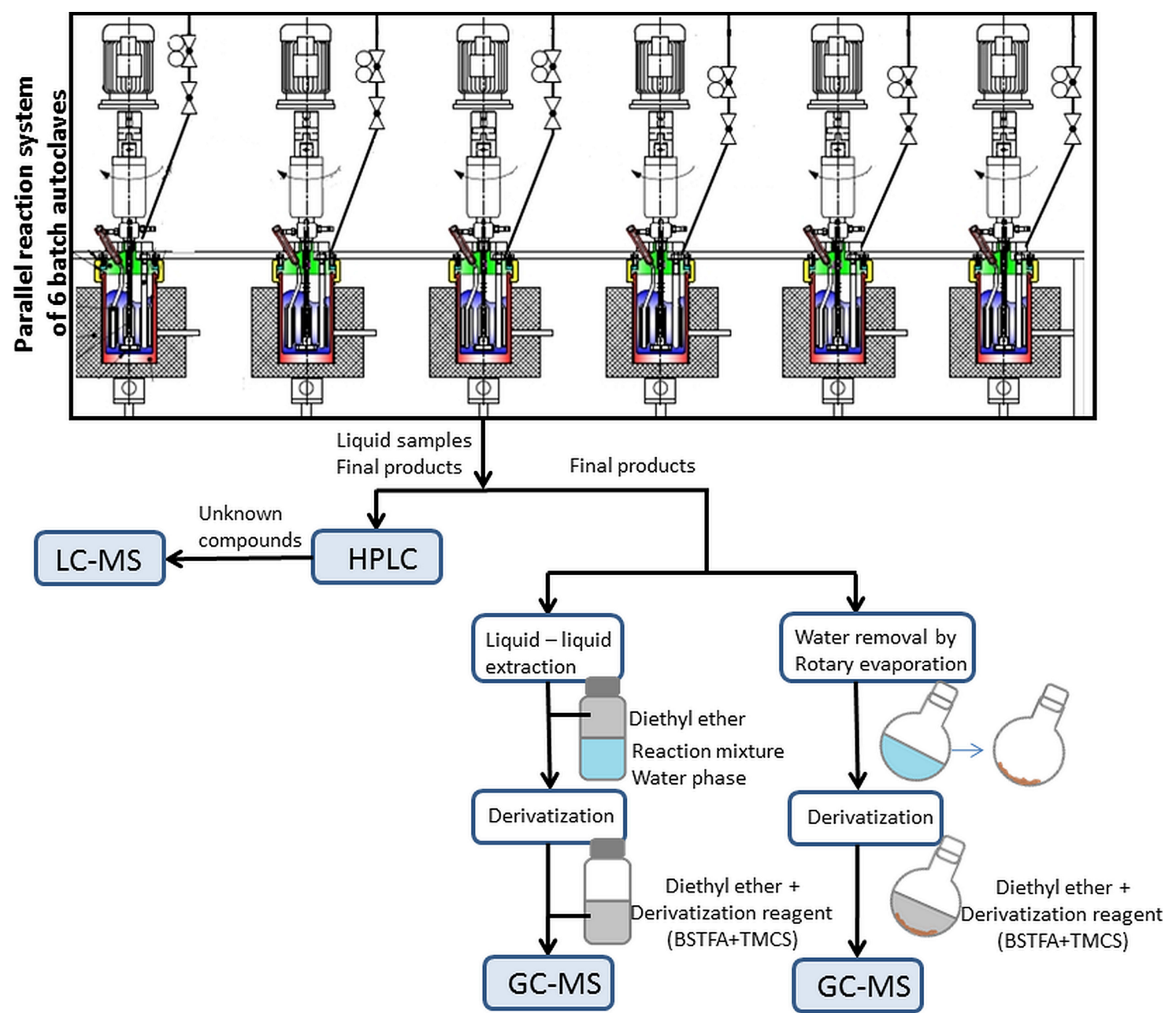

Figure 7. A parallel reaction system of 6 batch reactors and analytic methods with additional sample (pre)treatments.

The final product from the reactor vessel was furthermore treated by two different protocols for GC-MS analysis in order to remove water and convert the components into more volatile derivatives. Besides the increase of volatility, peak shape and separation is also improved with derivatization, especially for (di)carboxylic acids. Silylating reagent (BSTFA + TMCS, 99:1, Sigma Aldrich, St. Luis, $\mathrm{MO}, \mathrm{USA})$ and esterification reagent $(\mathrm{MeOH}+\mathrm{HCl}$, Sigma Aldrich, St. Luis, $\mathrm{MO}$, USA) were used for derivatization. Two different approaches were applied for GC-MS sample preparation. Firstly, 
extraction in diethyleter from aqueous solution was used (in 1:1 $v / v$ ratio). The diethyl ether phase was separated and the derivatization agent was added in abundance regarding the stoichiometry of compounds in the reaction mixture. The second approach included water removal by rotary evaporator, addition of the derivatization agent, and diethyl ether to dissolve derivatized compounds. Extracted and derivatizated compounds were analyzed by GC-MS, equipped with a nonpolar column (ZebronTM ZB-5MS, length $60 \mathrm{~m}$, diameter $0.25 \mathrm{~mm}$, film thickness $0.25 \mu \mathrm{m}$ ), and the FID (flame ionization detector, Shimadzu, Kyoto, Japan) detector. Temperature programmed method was used for the analyses of derivatized samples, where the column oven was initially kept at $313 \mathrm{~K}$ for $7.2 \mathrm{~min}$, then increased to $383 \mathrm{~K}$ with a heating rate of $25 \mathrm{~K} \mathrm{~min}^{-1}$, heated to $498 \mathrm{~K}$ at a rate of $18 \mathrm{~K} \mathrm{~min}^{-1}$, and finally to $553 \mathrm{~K}$ at a rate of $40 \mathrm{~K} \mathrm{~min}^{-1}$, where the temperature was kept constant for additional $13 \mathrm{~min}$. The injector and detector were maintained at $568 \mathrm{~K}$; the injection volume was $1 \mu \mathrm{L}$ and the split ratio was set to 15 . Mass spectrometry (MS) was used for identification of intermediates and products, where each compound was sent through the ion source and the fragments were separated and scanned in the range from 35 to $500 \mathrm{~m} / z$ and compared to the FFNSC (Flavour and Fragnance Natural and Synthetic Compounds) and NIST14 (National Institute of Standards and Technology) libraries.

\section{Conclusions}

Hydrodeoxygenation of mucic acid, one of the promising bio-based chemicals in value-added chemicals, showed good potential. Using a cheaper NiMo catalyst at slightly higher temperatures delivered better results compared to the more active noble metal catalysts at lower temperatures. Even though $\mathrm{NiMo} / \gamma-\mathrm{Al}_{2} \mathrm{O}_{3}$ catalyst is a well-known industrial catalyst for $\mathrm{HDO}$ reactions, many authors pointed out that its support (alumina) is not stable in the water environment. For short $\left(t_{\text {total }}=3.5 \mathrm{~h}\right)$ experiments it worked very well without any deactivation. Under aqueous conditions mucic acid readily forms an equilibrium with mucic-1,4-lactone that is subsequently hydrogenated into galacturonic and galactonic acid in $\mathrm{H}_{2}$ atmosphere. The main products detected in the catalytic HDO process were tetrahydro-2-furfuryl alcohol (max. yield of 10.1\%), adipic acid (max. yield of 4.3\%), 2-hydroxy pentanoic acid, levulinic acid, 2-furoic acid, 2-pentenoic acid, and 2-hydroxy hexanoic acid. Many of them represent important platform chemicals, specifically for the polymer industry. Noble metals (especially $\mathrm{Rh}$ and $\mathrm{Ru}$ ) proved to be very active for the conversion of mucic acid into hydrocarbons. It turned out that the pore diameter width had an important role on the conversion due to mass transfer limitations. Nevertheless, the highest yield of adipic acid did not exceed $5 \mathrm{~mol} \%$. However, we are the first to report formation of adipic acid in an aqueous system with heterogeneous catalysts.

The main issue using an oxidized cellulose-based feedstock, such as mucic and glucaric acid, is the solubility, which is very low (or negligible) in water, alcohols, and organic solvents. The aqueous environment is eco-friendly, but on the other hand could degrade the $\mathrm{Al}_{2} \mathrm{O}_{3}$ structure of the catalyst support, resulting in lower overall activity. From an environmental point of view, the developed process is eco-friendly, since is uses water as a solvent. It offers a good starting point for producing important bio-based chemicals from nonedible lignocellulosic biomass. Lignocellulosic biomass or bio-waste is a sustainable feedstock that can replace oil and could be included in the circular economy system with a minor environmental impact.

Supplementary Materials: The following are available online at http:/ /www.mdpi.com/2073-4344/9/3/286/s1. Figure S1: Derivatized compounds, obtained by GC-MS analysis. Figure S2: Chromatogram of mucic acid standard and MS spectrum of the detected peaks. Figure S3: Adipic acid chromatogram and MS spectrum. Figure S4: Chromatogram and MS spectrum of liquid sample. Figure S5: Conversions of mucic acid over noble and transition metals in the temperature range $125-175^{\circ} \mathrm{C}$. Figure S6: Summarized conversions of mucic acid and its lactone over noble and transition metals in the temperature range $125-175^{\circ} \mathrm{C}$. Figure S7: (a) HPLC mobile phase flow a combination of water phase $\left(2.5 \mathrm{mM} \mathrm{H}_{2} \mathrm{SO}_{4}\right)$ and organic phase (100\% acetonitrile) and (b) GC temperature program with different heating ramps. Figure S8. HPLC chromatogram of the final product over neutral C support. Figure S9. HPLC chromatogram of the final product over acidic alumina support. Figure S10. Concentrations of mucic acid, lactones, galacturonic and galactonic acid over different supports. Figure S12. TEM image of Rh/C. Figure S13. NH3-TPD of catalysts on different supports. Figure S14. Chromatograms of 
products, obtained in the experiment with fresh and recycled $\mathrm{NiMo} / \gamma-\mathrm{Al} 2 \mathrm{O} 3$ catalyst. Figure S15. Conversion of mucic acid and yield of 2-furoic acid (the highest detected peak on HPLC) over fresh (1) and recycled catalyst (2). Table 1. NiMo/Al2O3 catalyst characterization results after the sulphidation [5]. Table S2. Concentration of metal sites and acidic sited. Table S3. Selectivity data for each compound detected in the esterified phase over carbon supported metal catalysts, analyzed by GCMS. Table S4. Selectivity data for each compound detected in the esterified phase over silica supported metal catalysts, analyzed by GCMS. Table S5. Selectivity data for each compound detected in the esterified phase over alumina supported metal catalysts, analyzed by GCMS.

Author Contributions: B.H. performed the experiments, developed the analytic methods, and wrote the original draft paper. M.G. coordinated the work and reviewed and edited the paper. B.L. supervised the work.

Funding: This research was funded by the Slovenian Research Agency (Program P2-0152).

Acknowledgments: The authors gratefully acknowledge the financial support of the Slovenian Research Agency (ARRS) through the Program P2-0152. The work was partially carried out within the RDI (Research, Development and Innovation) project Cel. Cycle: Potential of Biomass for Development of Advanced Materials and Bio-based Products, which is co-financed by the Republic of Slovenia, Ministry of Education, Science and Sport, and the European Union through the European Regional Development Fund, 2016-2020. The authors also gratefully acknowledge Anže Prašnikar and Urška Kavčič for their excellent catalyst characterization work.

Conflicts of Interest: The authors declare no conflict of interest.

\section{References}

1. Cavani, F. Chemicals and Fuels from Bio-based Building Blocks; Wiley-VCH Verlag GmbH \& Company KGaA: Weinheim, Germany, 2016.

2. Philp, J.C.; Ritchie, R.J.; Allan, J.E.M. Biobased chemicals: the convergence of green chemistry with industrial biotechnology. Trends Biotechnol. 2013, 31, 219-222. [CrossRef] [PubMed]

3. Werpy, T.; Petersen, G.; Aden, A.; Bozell, J.; Holladay, J.; White, J.; Manheim, A.; Eliot, D.; Lasure, L.; Jones, S. Top Value Added Chemicals from Biomass. Volume 1-Results of Screening for Potential Candidates from Sugars and Synthesis Gas; Department of Energy: Washington, DC, USA, 2004.

4. Van Haveren, J.; Scott, E.L.; Sanders, J. Bulk chemicals from biomass. Biofuels Bioprod. Biorefining 2008, 2, 41-57. [CrossRef]

5. Lederkremer, R.; Marino, C. Acids and Other Products of Oxidation of Sugars. Adv. Carbohydr. Chem. Biochem. 2004, 58, 199-306.

6. Boussie, T.R.; Dias, E.L.; Fresco, Z.M.; Murphy, V.J.; Shoemaker, J.; Archer, R.; Jiang, H. Production of Adipic Acid and Derivatives from Carbohydrate-Containing Materials. U.S. Patent 8,501,989, 6 August 2010.

7. Asikainen, M.; Thomas, D.; Harlin, A. Method for producing muconic acids and furans from aldaric acids. U.S. Patent 15/317,983, 18 May 2017.

8. Yoshinao, N.; Sibao, L.; Masazumi, T.; Keiichi, T. Catalytic Total Hydrodeoxygenation of Biomass-Derived Polyfunctionalized Substrates to Alkanes. ChemSusChem 2015, 8, 1114-1132.

9. Agblevor, F.A.; Jahromi, H. Aqueous-Phase Synthesis of Hydrocarbons from Furfural Reactions with Low-Molecular-Weight Biomass Oxygenates. Energy Fuels 2018, 32, 8552-8562. [CrossRef]

10. Jahromi, H.; Agblevor, F.A. Hydrodeoxygenation of Aqueous-Phase Catalytic Pyrolysis Oil to Liquid Hydrocarbons Using Multifunctional Nickel Catalyst. Ind. Eng. Chem. Res. 2018, 57, 13257-13268. [CrossRef]

11. Liang, C.; Donald, E. Kiely D-Glucaric Acid Esters/Lactones Used in Condensation Polymerization to Produce Hydroxylated Nylons-A Qualitative Equilibrium Study in Acidic and Basic Alcohol Solutions. J. Carbohydr. Chem. 1994, 13, 585.

12. Si, Z.; Zhang, X.; Wang, C.; Ma, L.; Dong, R. An Overview on Catalytic Hydrodeoxygenation of Pyrolysis Oil and Its Model Compounds. Catalysts 2017, 7, 169. [CrossRef]

13. Han, X.; Guo, Y.; Liu, X.; Xia, Q.; Wang, Y. Catalytic conversion of lignocellulosic biomass into hydrocarbons: a mini review. Catal. Today 2018. [CrossRef]

14. Van Looij, F.; van der Laan, P.; Stork, W.H.J.; DiCamillo, D.J.; Swain, J. Key parameters in deep hydrodesulfurization of diesel fuel. Appl. Catal. A Gen. 1998, 170, 1-12. [CrossRef]

15. Furimsky, E. Catalytic hydrodeoxygenation. Appl. Catal. A Gen. 2000, 199, 147-190. [CrossRef]

16. Şenol, O.İ; Ryymin, E.-M.; Viljava, T.-R.; Krause, A.O.I. Effect of hydrogen sulphide on the hydrodeoxygenation of aromatic and aliphatic oxygenates on sulphided catalysts. J. Mol. Catal. A Chem. 2007, 277, 107-112. [CrossRef] 
17. Boussie, T.R.; Diamond, D.M.; Dias, E.; Murphy, V. Synthesis of Adipic Acid Starting from Renewable Raw Materials. In Chemicals and Fuels from Bio-Based Building Blocks; Wiley-Blackwell: Hoboken, NJ, USA, 2016; pp. 151-172. ISBN 9783527698202.

18. Yang, M.; Somorjai, G.A. Adsorption and Reactions of C6 Hydrocarbons at High Pressures on Pt(111) Single-Crystal Surfaces Studied by Sum Frequency Generation Vibrational Spectroscopy: Mechanisms of Isomerization and Dehydrocyclization of n-Hexane. J. Am. Chem. Soc. 2004, 126, 7698-7708. [CrossRef] [PubMed]

19. Hočevar, B.; Grilc, M.; Huš, M.; Likozar, B. Mechanism, ab initio calculations and microkinetics of hydrogenation, hydrodeoxygenation, double bond migration and cis-trans isomerisation during hydrotreatment of $\{C 6\}$ secondary alcohol species and ketones. Appl. Catal. B Environ. 2017, 218, 147-162. [CrossRef]

20. Hočevar, B.; Grilc, M.; Huš, M.; Likozar, B. Mechanism, ab initio calculations and microkinetics of straight-chain alcohol, ether, ester, aldehyde and carboxylic acid hydrodeoxygenation. Chem. Eng. J. 2019, 359, 1339-1351. [CrossRef]

21. Grilc, M.; Likozar, B. Levulinic acid hydrodeoxygenation, decarboxylation and oligmerization over $\mathrm{NiMo} / \mathrm{Al} 2 \mathrm{O} 3$ catalyst to bio-based value-added chemicals: Modelling of mass transfer, thermodynamics and micro-kinetics. Chem. Eng. J. 2017, 330, 383-397. [CrossRef]

22. Lefèvre, G.; Duc, M.; Lepeut, P.; Caplain, R.; Fédoroff, M. Hydration of $\gamma$-Alumina in Water and Its Effects on Surface Reactivity. Langmuir 2002, 18, 7530-7537. [CrossRef]

23. Petek, U.; Ruiz-Zepeda, F.; Bele, M.; Gaberšček, M. Nanoparticles and Single Atoms in Commercial Carbon-Supported Platinum-Group Metal Catalysts. Catalysts 2019, 9, 134. [CrossRef]

24. Tan, M.; Yang, G.; Wang, T.; Vitidsant, T.; Li, J.; Wei, Q.; Ai, P.; Wu, M.; Zheng, J.; Tsubaki, N. Active and regioselective rhodium catalyst supported on reduced graphene oxide for 1-hexene hydroformylation. Catal. Sci. Technol. 2016, 6, 1162-1172. [CrossRef]

25. Linke, R.; Curulla, D.; Hopstaken, M.J.P.; Niemantsverdriet, J.W. CO/Rh(111): Vibrational frequency shifts and lateral interactions in adsorbate layers. J. Chem. Phys. 2001, 115, 8209-8216. [CrossRef]

26. De Mongeot, F.B.; Scherer, M.; Gleich, B.; Kopatzki, E.; Behm, R.J. CO adsorption and oxidation on bimetallic $\mathrm{Pt} / \mathrm{Ru}(0001)$ surfaces-A combined STM and TPD/TPR study. Surf. Sci. 1998, 411, 249-262. [CrossRef]

27. LaRue, J.L.; Katayama, T.; Lindenberg, A.; Fisher, A.S.; Öström, H.; Nilsson, A.; Ogasawara, H. THz-Pulse-Induced Selective Catalytic CO Oxidation on Ru. Phys. Rev. Lett. 2015, 115, 36103. [CrossRef] [PubMed]

28. Grenoble, D.C.; Estadt, M.M.; Ollis, D.F. The chemistry and catalysis of the water gas shift reaction: 1. The kinetics over supported metal catalysts. J. Catal. 1981, 67, 90-102. [CrossRef]

29. Grilc, M.; Likozar, B.; Levec, J. Hydrodeoxygenation and hydrocracking of solvolysed lignocellulosic biomass by oxide, reduced and sulphide form of NiMo, Ni, Mo and Pd catalysts. Appl. Catal. B Environ. 2014, 150, 275-287. [CrossRef]

30. Taylor, W.A.; Acree, S.F. The Equilibrium between Mucic Acid and Its Lactones. J. Phys. Chem. 1915, 20, 118-120. [CrossRef]

31. Brown, J.M.; Manley-Harris, M.; Field, R.J.; Kiely, D.E. An NMR Study of the Equilibration of d-Glucaric Acid with Lactone Forms in Aqueous Acid Solutions. J. Carbohydr. Chem. 2007, 26, 455-467. [CrossRef]

32. De Jong, E.; Dam, M.A.; Sipos, L.; Gruter, G.-J.M. Furandicarboxylic Acid (FDCA), A Versatile Building Block for a Very Interesting Class of Polyesters. Biobased Monomers Polym. Mater. 2012, 105, 1-13.

33. Marcus, R.; Regina, P. Cellulose-Based Sustainable Polymers: State of the Art and Future Trends. Macromol. Rapid Commun. 2011, 32, 1299-1311.

34. Unnikrishnan, P.; Srinivas, D. Chapter 3-Heterogeneous Catalysis A2-Joshi, S. In Industrial Catalytic Processes for Fine and Specialty Chemicals; Ranade, V.V., Ed.; Elsevier: Amsterdam, The Netherlands, 2016; pp. 41-111, ISBN 978-0-12-801457-8.

35. Watson, M.J. Platinum Group Metal Catalysed Hydrodeoxygenation Of Model Bio-oil Compounds. Johnson Matthey Technol. Rev. 2014, 58, 156-161. [CrossRef]

36. Lee, H.; Kim, H.; Yu, M.J.; Ko, C.H.; Jeon, J.-K.; Jae, J.; Park, S.H.; Jung, S.-C.; Park, Y.-K. Catalytic Hydrodeoxygenation of Bio-oil Model Compounds over Pt/HY Catalyst. Sci. Rep. 2016, 6, 28765. [CrossRef]

37. Levene, P.A.; Simms, H.S. Lactone Formation from Mono- and Dicarboxylic Sugar Acids. J. Biol. Chem. 1925, $65,31-47$. 
38. Trueba, M.; Trasatti, S.P. $\gamma$-Alumina as a Support for Catalysts: A Review of Fundamental Aspects. Eur. J. Inorg. Chem. 2005, 17, 3393-3403. [CrossRef]

39. Leofanti, G.; Padovan, M.; Tozzola, G.; Venturelli, B. Surface area and pore texture of catalysts. Catal. Today 1998, 41, 207-219. [CrossRef]

40. Trimm, D.L.; Stanislaus, A. The control of pore size in alumina catalyst supports: A review. Appl. Catal. 1986, 21, 215-238. [CrossRef]

41. He, Z.; Wang, X. Hydrodeoxygenation of model compounds and catalytic systems for pyrolysis bio-oils upgrading. Catal. Sustain. Energy 2012, 1, 28. [CrossRef]

42. Chen, L.; Zhu, Y.; Zheng, H.; Zhang, C.; Zhang, B.; Li, Y. Aqueous-phase hydrodeoxygenation of carboxylic acids to alcohols or alkanes over supported Ru catalysts. J. Mol. Catal. A Chem. 2011, 351, 217-227. [CrossRef]

43. Ruddy, D.A.; Schaidle, J.A.; Ferrell Iii, J.R.; Wang, J.; Moens, L.; Hensley, J.E. Recent advances in heterogeneous catalysts for bio-oil upgrading via "ex situ catalytic fast pyrolysis": Catalyst development through the study of model compounds. Green Chem. 2014, 16, 454-490. [CrossRef]

44. Xiong, H.; Pham, H.N.; Datye, A.K. Hydrothermally stable heterogeneous catalysts for conversion of biorenewables. Green Chem. 2014, 16, 4627-4643. [CrossRef]

45. Van Cleve, T.; Underhill, D.; Veiga Rodrigues, M.; Sievers, C.; Medlin, J.W. Enhanced Hydrothermal Stability of $\gamma$-Al2O3 Catalyst Supports with Alkyl Phosphonate Coatings. Langmuir 2018, 34, 3619-3625. [CrossRef]

(c) 2019 by the authors. Licensee MDPI, Basel, Switzerland. This article is an open access article distributed under the terms and conditions of the Creative Commons Attribution (CC BY) license (http:/ / creativecommons.org/licenses/by/4.0/). 